\title{
Referential Choice in the Discourse of Native, Near-Native and Non-Native Speakers of English: Revisiting Kibrik's Approach
}

\author{
Amr M. El-Zawawy \\ Dept. of English, Faculty of Education \\ Alexandria University \\ amrzuave@yahoo.com
}

\begin{abstract}
The present paper aims at re-applying Kibrik's Framework (1999, 2000, 2009, 2011) with some considerable modifications as a new cognitive linguistic channel for evaluating certain textual/discoursal representations. This is achieved through adding the acoustic dimension (with several sub-divisions) to Kibrik's Model/Framework, and applying the new version to certain speeches. These speeches are so selected as to represent outputs by native, near-native and nonnative speakers of English. Major conclusions exhibit that, in the case of nativespeaker discourse, the missing category of FULL NP OR PRONOUN can be compensated by the WM operating as control or maximally in full capacity to accommodate the excessive dependence on cataphora. This is not the case for nearnative discourse. The net result is a WM operating on its capacity level, and not in control of the discourse, since little discourse segments, so to say, remain active. An even less coherent discourse is produced by non-native speakers. Both categories of FULL NP ONLY and PRONOUN ONLY are not there, which highlights the incomplete operations of the WM.
\end{abstract}

Keywords: Kibrik Neural Framework; WM (Working Memory); coherence; activation; acoustic 


\section{Introduction}

Referential choice is one way of investigating the structure of any text or even discourse. It provides valuable insights into how texts/discourses are organized, and how they cohere (cf. Tomlin, 1987) in addition to memory activation. Referential choice, moreover, relates to how anaphora refers to other textual spans and how this operates as an indication of neural and cognitive activity, viz. how it relates to memory functions. This functioning entails capacity, control, and forgetting (Kibrik, 1999, 2000, 2009, 2011; Grüning and Kibrik, 2005). Thus, it can provide a model of optimal text/discourse structure, based on how referential choice reflects human memory in the course of text/discourse making.

Several models have been proposed to account for referential choice in text/discourse studies. Chief among them are Rhetorical Structure Theory (henceforth RST, Mann and Thompson, 1992), Centering Theory (Grosz and Sidner, 1986) and Kibrik's Neural Calculative Framework (1999). RST is the most prominent model, being the most elaborate, yet it does not furnish specific numerical values to detect memory failures and/or successes. The Centering Theory, in turn, is numerical, but it starts from similar premises to RST, and is mainly computational in nature, with little attention to memory as a fundamental component of the human cognitive system. Kibrik's Framework, however, is more amenable to application within the context of human neural activity, since it sets clear-cut values for memory activity. It is also more comprehensive, since it pays some attention to prosody as a complementary feature of cognitive discourse analysis. Yet Kibrik's Framework is still in need of being more crystallized into an operational apparatus capable of approximating prosodic featural values alongside discourse neural activity values.

The task in the present paper is to re-apply Kibrik's Framework with some considerable modifications as a new cognitive linguistic channel for evaluating certain textual/discoursal representations. This is achieved through modifying Kibrik's Model/Framework, and applying the new version to certain speeches. These speeches are so selected as to represent outputs by native, near-native and non-native speakers of English. The ultimate goal of this (re)application is to provide a picture of how cognitive discourse analysis (being grounded in 
referential choice mechanisms) is capable of exploring how neural activity can be detected via coreference in text/discourse.

\section{Statement of the Problem and Research Questions}

The present paper focuses on re-applying Kibrik's (1999, 2000, 2009, 2011) Framework with some considerable modifications (especially, the acoustic dimension of the voiceprint) as a new cognitive linguistic channel for evaluating certain oral textual/discoursal representations. Consequently, the present research seeks to answer the following questions:

1. How can Kibrik's $(1999,2000,2009,2011)$ Framework be modified in order to accommodate the acoustic dimension and other features to reveal much about working memory and activation?

2. How can the modified version of Kibrik's (1999, 2000, 2009, 2011) Framework be applied to native, near-native and non-native discourse in terms of referential choice, memory activation and oral discourse structure?

\section{Research Objectives}

The ultimate goal of the(re)application of Kibrik's (1999, 2000, 2009, 2011) Framework as modified in the present paper is to provide a picture of how cognitive discourse analysis (being grounded in referential choice mechanisms) is capable of exploring how neural activity can be detected via coreference in oral text/discourse. This ultimate goal, however, subsumes the following minor objectives:

1. Exploring how referential choice (as a reflection of memory activation) can be a demarcating line among native, near-native and non-native discourses.

2. Exploring how the acoustic dimension (as exemplified by the voiceprint) can be an added indication of the Full Activation Score as proposed in the present paper.

\section{Approaches to Referential Choices}

\subsection{Rhetorical Structure Theory}


RST (Mann and Thompson, 1992) is a major model of investigating referential choice across a certain text/discourse. It adopts the notion of text spans (discourse segments) as the building blocks of discourse. These spans are linked together by several schemata according to three principles:

- completeness: The set contains one schema that contains a set of text spans constituting the entire text.

- connectedness: Except for the entire text as a text span, each text span in the analysis is either a minimal unit or a constituent of another schema of the analysis.

- uniqueness: Each schema consists of a different set of text spans, and within a multi-relation schema each relation applies to a different set of text spans.

- adjacency: The text spans of each schema constitute one text span. Taken together, these principles ensure RST analyses to be trees with text spans (discourse segments) interpreted as nodes. Thus, parent nodes are located above their children nodes in Figure 1 below:

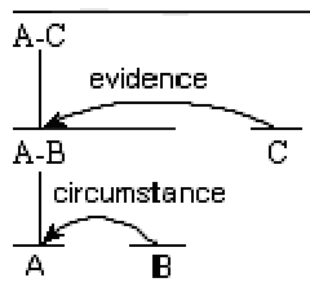

Fig. 1. Example of a rhetorical tree (Fox 1987)

RST also distinguishes between two seminal notions in discourse, namely nuclei and satellites. Nuclei are more central to the writer's purpose, less easy to substitute and more necessary for the understanding of a text. Contrary to nuclei, satellites can be replaced without any significant change to the text function. They depend in their meaning on other elements. Moreover, The RST assumes a number of rhetorical relations between discourse units which can be either symmetrical (multinuclear) or asymmetrical (mononuclear) ${ }^{1}$. Mononuclear relations connect rhetorical relations with one nucleus and one satellite, whereas multinuclear rhetorical relations link several nuclei, but not satellites.

\footnotetext{
${ }^{1}$ These rhetorical relations are usually construed as schemata (cf. Chiarcos and Krasavina, 2005) 
Furthermore, the term "rhetorical" is influenced by the hypothesis that rhetorical relations are like semantic relations between the main and adjunct clauses in complex sentences, and extend to the discourse level, that is, can connect discourse units regardless of sentence boundaries or length, being driven by the speaker's communicative goals, rather than by the principles of syntax.

Text spans are likewise classified into elementary discourse units (henceforth EDUs). EDUs are usually clauses (cf. Carlson et al. 2003). As in Figure 1, there are three EDUs, A, B and C, where A and B form, connected by a CIRCUMSTANCE relation, a larger discourse segment $\mathrm{A}-\mathrm{B}$. In turn, $\mathrm{A}-\mathrm{B}$ and $\mathrm{C}$ are connected by an EVIDENCE relation. Elementary discourse units are connected by rhetorical relations into higher order units, among which the same kind of rhetorical relations hold. Discourse units hierarchically incrementally grow to the level of discourse global structure, and eventually the discourse as a whole.

Based on RST, Fox (1987a) provided a numerical approach to the selection of referential devices, suggestion that the process is based on the hierarchical structure of discourse. She calculated a rhetorical distance to the antecedent on the basis of a rhetorical structure constructed for a text according to RST. In terms of RST, each text can be represented as a tree graph consisting of nodes (discourse units) and connections (rhetorical relations). Rhetorical distance between nodes A and $\mathrm{B}$ is then the number of horizontal steps one needs to make to reach $\mathrm{A}$ from $\mathrm{B}$ along the graph (as is illustrated by Figure 1 above).

\subsection{Centering Theory (Grosz and Sidner, 1986)}

Grosz and Sidner (1986) distinguish among three components of discourse structure: linguistic structure, intentional structure, and attentional state. The first component, the linguistic structure, is supposed to group utterances into discourse segments, while the second component, the intentional structure, consists of discourse segment purposes and the relations between them. The third component, the attentional state, is an abstraction of the discourse participants' focus of attention, and records the objects, properties, and relations that are very important at a given point in the discourse. 
'Centering' is an element of the local level and pertains to the interaction between the form of linguistic expression and local discourse coherence. In particular, it relates local coherence to choice of referring expression (or anaphora, such as pronouns in contrast to definite description or proper name). The term is based on the idea that differences in coherence correspond in part to the different demands for inference made by different types of referring expressions, given a particular attentional state (El-Zawawy, 2016).

$\mathrm{Hu}$ and Pan (2001, p. 5) prefer to focus on the formalisms inherent in the Centering Theory. They provide the following constraints and rules:

\section{1- Constraints:}

a. There is precisely one backward-looking center $\mathrm{Cb}\left(\mathrm{U}_{\mathrm{i}}, \mathrm{D}\right)$.

b. Every element of the forward centers list, $\mathrm{Cf}\left(\mathrm{U}_{\mathrm{i}}, \mathrm{D}\right)$, must be realized in $\mathrm{U}_{\mathrm{i}}$.

c. The center, $\mathrm{Cb}\left(\mathrm{U}_{\mathrm{i}}, \mathrm{D}\right)$, is the highest-ranked element of $\mathrm{Cf}\left(\mathrm{U}_{\mathrm{i}-1}, \mathrm{D}\right)$ that is realized in $U_{i}$.

2- Rules:

For each $\mathrm{U}_{\mathrm{i}}$ in a discourse segment $\mathrm{D}$ consisting of utterances $\mathrm{U}_{1}, \ldots, \mathrm{U}_{\mathrm{m}}$.

a. If some element of $\mathrm{Cf}\left(\mathrm{U}_{\mathrm{i}-1}, \mathrm{D}\right)$ is realized as a pronoun in $\mathrm{U}_{\mathrm{i}}$, then so is $\mathrm{Cb}$ $\left(\mathrm{U}_{\mathrm{i}}, \mathrm{D}\right)$.

b. Transition states are ordered. The CONTINUE transition is preferred to the RETAIN transition, which is preferred to the SMOOTH-SHIFT transition, which is preferred to the ROUGH-SHIFT transition.

It is noteworthy that Moser and Moore (1996), and Tetreault and Allen (2003) attempted a new understanding of Grosz and Sidner's model in terms of RST. They regarded RST-nuclearity as corresponding to and Grosz and Sidner's (1986) DOMINANCE, thus equating DOMINANCE relations with mononuclear (subordinating) RST relations and SATISFACTION-PRECEDENCE with multinuclear (coordinating) 


\section{REFERENTIAL CHOICE IN THE DISCOURSE OF NATIVE, NEAR-NATIVE AND NON-NATIVE SPEAKERS OF ENGLISH: REVISITING KIBRIK'S APPROACH}

RST relations. Marcu (2000, p. 527) also suggested an isomorphic mapping between DOMINANCE and RST-subordination, and a (mono-directional) homomorphism transforming SATISFACTION-PRECEDENCE into multinuclear relations. Yet Chiarcos and Krasavina (2005) maintain that this mapping is problematic, since both theories differ with respect to discourse granularity.

However, the two theories considerably differ in their tenets. RST adopts the notion of text spans (discourse segments) as the building blocks of discourse, while the Centering Theory does focus on the attentional span as detected from the most salient segment of discourse, i.e. the 'center'. RST also distinguishes between two seminal notions in discourse, namely nuclei and satellites, which is not mentioned in the Centering Theory. Furthermore, the term "rhetorical" is influenced by the hypothesis that rhetorical relations are like semantic relations between the main and adjunct clauses in complex sentences, and extend to the discourse level, that is, can connect discourse units regardless of sentence boundaries or length, being driven by the speaker's communicative goals, rather than by the principles of syntax. This emphasizes that RST is geared towards a non-linear analysis of discourse, while the Centering Theory is based on lists including centers ranked according to two main criteria: grammatical function and linear order.

\subsection{Kibrik's Approach}

In a series of papers, Kibrik (1999, 2000, 2009, 2011; Grüning and Kibrik, 2005) proposed a new method of calculating rhetorical distance, using the shortest path from an anaphor to its antecedent along the rhetorical tree. Kibrik also argues that rhetorical distance is a strong factor for licensing the use of pronouns vs. Definite NPs in discourse. His approach is based on the hypothesis that the level of a specific referent's activation at a particular point of discourse depends on multiple factors. Each of these factors contributes (in a positive or negative numerical way) to the ultimate activation score of the referent. Factors like animacy and protagonisthood are, moreover, included. Originally developed for Russian discourse progression, the numerical model employed to calculate activation score is supposed to imitate the cognitive interplay of activation factors during discourse production. He maintains that his model could be used to explain and predict 
discourse phenomena implications for more general cognitive issues, including the three processes involved in working memory (WM) operations:

- CAPACITY: how much information can there be in WM at one time

- CONTROL: what is the mechanism through which information enters WM

- FORGETTING: what is the mechanism through which information quits WM

He proposes 'activation score' (AS) as a numerical value to determine the status of the referent in the speaker's WM. Thus, he claims that if the AS is in the middle of a scale, a pronoun is unlikely (probably depending on the idiolect), and if AS is low, pronouns are ruled out. This scale for English discourse is envisaged as follows:

\begin{tabular}{l|c|c|c|c|c}
$\begin{array}{l}\text { Referential } \\
\text { device: }\end{array}$ & Full NP only & $\begin{array}{c}\text { Full NP, } \\
\text { ?pronoun }\end{array}$ & $\begin{array}{c}\text { Either full NP } \\
\text { or pronoun }\end{array}$ & $\begin{array}{c}\text { Pronoun, }{ }^{\text {ffull }} \\
\text { NP }\end{array}$ & $\begin{array}{c}\text { Pronoun } \\
\text { only }\end{array}$ \\
\hline AS: & $0-0.2$ & $0.3-0.5$ & $0.6-0.7$ & $0.8-1.0$ & $1.1+$
\end{tabular}

Fig. 2: Kibrik’s (1999) activation scores for each referential device

Although his model is built on a pool of other theories and heuristic measures, it does not make it clear how prosody can be effectively incorporated into the calculative nature of the AS. This and other shortcomings are to be remedied in the present paper (see section 6 below).

\section{Review of the Literature}

Several studies have been carried out on the importance of utilizing referential choices and co-reference as a tool to detect neural activity, particularly the working memory, in discourse. Chief among these studies are the early approaches by Chafe (1976, 1994), Givón (1983), Fox (1983) and Tomlin (1987).

Chafe $(1976,1994)$ studied referential choice within the framework of Givenness, Contrastiveness, Subjects, Topics, and Point of View. Givenness refers to old versus new information, which substantiates the principle of contrastivenss: there are pieces of information that are already activated and others newly activated. 
These are related to subjecthood as a syntactic criterion for the structure of a sentence and hence discourse. Thus, discourse can be reread as a number of topics that are so structured according to memory activation to reflect the speaker's point of view. Point of view is termed by him as 'empathy'. Accordingly, Chafe proposed some generalizations regarding empathy as follows:

1. If the speaker himself is part of the sentence, empathy will likely be with him.

2.Empathy for the addressee is more likely than empathy for a third party.

3Human referents are more likely to be empathized with Status as the focus of empathy is likely to coincide with subject status and definiteness.

Givón (1983) focuses on continuity in discourse as an approach to rhetorical distance and memory activation. He sees discourse as made up of topics and themes that ground the neural processes of activation, and seeks to bridge the gap through three continuities as representations of the macro and micro organizational levels of language.

(a) Thematic continuity

(b) Action continuity

(c) Topics/participants continuity

Persistence and decay are used as terms to indicate the continuity of discoursal references. Numerical values are provided for persistence and decay based on a number of observations Givon notes from different languages, particularly English and Spanish.

Fox (1983) follows a similar route. Her study deals with a number of syntactic devices which code the degree of topic-NP continuity in Biblical Hebrew discourse. She hypothesizes that that these devices hierarchize along a continuity/ predictability scale. This scale, in terms of the cross-linguistic ally most common syntactic construction. The devices are plotted on a continuum as follows:

\section{MOST CONTINUOUS}

zero anaphora

unstressed/clitic pronouns (verb agreement)

independent/stressed pronouns 
R-dislocated DEF-NP

DEF-NP

L-dislocated DEF-NP

passivized (subject) NP

Y-movement

indefinite NP

cleft/focused/contrasted NP

LEAST CONTINUOUS

Adopting the same notions of persistence and decay (as proposed by Givón, 1983), she concludes that human arguments consistently persist longer in subsequent discourse once they have been introduced into the register (by whatever means); and on the whole the subject and dative-benefactive cases, prototypically human, tend to mark topics that are likely to persist longer.

The same notions defined by Givón (1983) are further carried through to be included in Tomlin's (1987) insights. He sees topic continuity as a method of integrating the knowledge shared between the speaker and the reader/listener. This knowledge can be further articulated into focus and center-two notions that organize discourse management. This management process can be operationalized as to provide strategies for counting textual segments as numerical values for memory activation/activity.

A ground-breaking approach is provided by Kibrik and Grüning (2005). They review the then prevailing models of referential choice (including the ones cited above) and propose two alternative models of referential choice. The first approach of Kibrik $(1999,2000)$ is the cognitive calculative approach. It hypothesizes that referential choice depends on the referent's current activation score in the speaker's working memory. The activation score can be calculated as a sum of numeric contributions of individual activation factors, such as distance to the antecedent, protagonisthood, and the like. Accordingly, a predictive dependency between the activation factors and referential choice is taken as the major criterion. However, the two scholars admit that the calculative approach cannot address non-linear interdependencies between different factors. For this 
reason, they developed a mathematically more sophisticated neural network approach to the same set of data. They classified up to all but 4 instances correctly with respect to the actual referential choice. A pruning procedure allowed to produce a minimal network and revealed that out of ten input factors five were sufficient to predict the data almost correctly, and that the logical structure of the remaining factors can be simplified. They also concluded that costly input factors (such as rhetorical distance to the antecedent) could be replaced by those related to the linear antecedent, which can be more easily collected from a large corpus. What is significant about Kibrik and Grüning's model is the languages it used as training corpora. Their study applied the selected criteria to English and Russian, which yielded seminal results on languages of distant families.

Kibrik and Krasavina (2005) used the annotation scheme proposed in Krasavina and Chiarcos (2007). More recently, Kibrik et al. (2010) and Loukachevitch et al. (2011) developed the MoRA (Moscow Reference Annotation) scheme and conducted machine learning studies on the corpus data, looking into the basic referential choice (two-way choice between pronouns and full NPs) and the threeway choice between pronouns, proper names, and descriptions (Kibrik et al., 2010; Loukachevitch et al., 2011).

Yet all these studies have not yielded a computer application that can incorporate the prosodic dimension (such as voiceprint) into the investigation of discourse structure in general and referential choice in particular. The task in the present paper is to include voiceprint as a valid dimension to Kibrik's (1999, 2000, 2009, 2011) framework, which can be later used in any computer software geared towards the study of the structure of oral discourse.

\section{Modifying Kibrik's Attempt as an Avenue to a New Model}

The above review reveals that the models proposed for investigating referential choice are chiefly numerical, but the most elaborate of them is Kibrik's (2009). It allows both hierarchical and linear processing and justifies memory operations to a great extent. However, Kibrik's AS and rhetorical distance are not well-connected to prosody, especially voiceprint, as a valid criterion for the activation of memory neural operations. There are no values set for the prosodic features of the anaphor 
and its antecedent(s). It is therefore important to note that there is much demand for the incorporation of some prosodic features to enrich the analysis of referential choice and give them extra credibility. One way to do this is to compare the voice print of the speaker as a spectrum, and calculate the anaphors and their antecedents relative to it at the points/spans of discourse under study. Frequency level is a valid tool in this respect. It can be given numerical values that are double the potential referential form value (i.e. AS) when the identical frequency is detected between the anaphor and its antecedent. This can follow a continuum from identical frequency to completely different frequency, leading to a Full Activation Score (FAS) as a modification of AS (after Kibrik, 1999). The following table illustrates these values:

Table 1: A modification of Kibrik's (1999) activation scores across potential referential forms

\begin{tabular}{|c|c|c|c|c|c|}
\hline \multirow[t]{2}{*}{$\begin{array}{l}\text { POTENTIAL } \\
\text { REFERENTIAL } \\
\text { FORM/Frequenc } \\
\text { y level }\end{array}$} & $\begin{array}{l}\text { FULL } \\
\text { NP } \\
\text { ONLY }\end{array}$ & $\begin{array}{l}\text { FULL NP } \\
? \\
\text { PRONOU } \\
\text { N }\end{array}$ & $\begin{array}{l}\text { FULL NP } \\
\text { OR } \\
\text { PRONOU } \\
\mathrm{N}\end{array}$ & $\begin{array}{l}\text { PRONOU } \\
\mathrm{N} \text { ? NP }\end{array}$ & $\begin{array}{l}\text { PRONOU } \\
\text { N ONLY }\end{array}$ \\
\hline & $\begin{array}{l}\text { Identical } \\
\text { / Close / } \\
\text { Approxi } \\
\text { mate/ } \\
\text { Different } \\
\text { / } \\
\text { Complet } \\
\text { ely } \\
\text { different } \\
\text { frequenc } \\
\text { y }\end{array}$ & $\begin{array}{l}\text { Identical / } \\
\text { Close / } \\
\text { Approxima } \\
\text { te/ } \\
\text { Different / } \\
\text { Completely } \\
\text { different } \\
\text { frequency }\end{array}$ & $\begin{array}{l}\text { Identical / } \\
\text { Close / } \\
\text { Approxima } \\
\text { te/ } \\
\text { Different / } \\
\text { Completely } \\
\text { different } \\
\text { frequency }\end{array}$ & $\begin{array}{l}\text { Identical / } \\
\text { Close / } \\
\text { Approxima } \\
\text { te/ } \\
\text { Different / } \\
\text { Completely } \\
\text { different } \\
\text { frequency }\end{array}$ & $\begin{array}{l}\text { Identical / } \\
\text { Close / } \\
\text { Approxima } \\
\text { te/ } \\
\text { Different / } \\
\text { Completely } \\
\text { different } \\
\text { frequency }\end{array}$ \\
\hline $\begin{array}{l}\text { Full Activation } \\
\text { Score (FAS) }\end{array}$ & $0-0.4$ & $0.6-0.10$ & $0.12-0.14$ & $0.16-2$ & $2.2+$ \\
\hline
\end{tabular}

Thus, the FAS is to replace Kibrik's AS, which omits the significant influence of prosody on referential choices in discourse. It is noteworthy that Kibrik and Fedorova (2018) incorporate a 'prosodic portrait' in their analysis, yet they focus 
on two types of intonation only: a final falling (so-called period intonation) and a non-final falling (a falling comma intonation), claiming that this is a complete account of a spoken discourse presupposes a speaker's Prosodic Portrait, i.e. a range of his or her prosodic characteristics. They, however, do not specify how the values of this portrait are interwoven in their analysis. They also ignore the fact that voiceprint can be a more reliable criterion, where relative frequency levels, especially F0, are calculated. The components of the voice print consulted in the present study are as follows:

\section{Frequency domain:}

Lowest frequency

Highest frequency

Total bandwidth

2. Frequency sampling:

Number of frequency bands (bins)

Frequency step (bin width)

First frequency band around (bin centre at)

It is also of note to consider how the values for referential choice are compromised in order to provide the most accurate picture possible of coreference in the texts selected for the present study. The AS values, as proposed by Kibrik (1999), are evaluated alongside those provided by Huggingface.com, which is considered the most accurate software to date available for referential choice values (Wolf et al., 2019). When in doubt, debugging is used to detect anomalies.

\section{Methods and Materials}

\subsection{Corpora}

The present corpora are made up of six speeches by native, near-native and nonnative speakers of English. The first corpus comprises three speeches by male speakers, viz. Barack Obama at 9/11 Museum Dedication (2014), King Abdullah (2018) and Naguib Sawiris (2018), which represent outputs by native, near-native and non-native speakers of English, respectively. The second corpus consists of three speeches by female speakers, viz. Prime Minister Jacinda Ardern (2018), Queen Rania (2007) and Tzipi Livni (2018), which represent outputs by native, near-native and non-native speakers of English, respectively. The choice of male 


\section{REFERENTIAL CHOICE IN THE DISCOURSE OF NATIVE, NEAR-NATIVE AND NON-NATIVE SPEAKERS OF ENGLISH: REVISITING KIBRIK'S APPROACH}

versus female speakers is not meant to include the variable of linguistic polarization of the two genders, but to achieve a comprehensive picture of the two genders in terms of corpus preparation and valid results.

Since Barack Obama and Jacinda Ardern are native speakers, their texts were classified as 'native'. The other texts chosen and labeled as 'near-native' or 'native' were classified according to the mapping of the Flesch-Kincaid Grade Level with CEFR and Cambridge levels. Flesch-Kincaid Grade Level is a readability index, pointing to the difficulty of a text, while CEFR and Cambridge Levels refer to the proficiency level of a speaker of English. The following table summarizes the mapping for 'near-native' and 'native' texts as done electronically by https://readabilityformulas.com and compared with the criteria provided by linguapress.com:

Table 2: Kincaid Grade, CEFR and Cambridge Levels for near-native and nonnative speakers

\begin{tabular}{|l|l|l|}
\hline Text & $\begin{array}{l}\text { Flesch-Kincaid Grade } \\
\text { Level }\end{array}$ & $\begin{array}{l}\text { CEFR and Cambridge } \\
\text { levels }\end{array}$ \\
\hline King Abdullah & 59.8 & C1 Advanced \\
\hline Queen Rania & 58.9 & C1 Advanced \\
\hline Naguib Sawiris & 78.1 & B1 intermediate \\
\hline Tzipi Livni & 81.3 & A2 elementary \\
\hline
\end{tabular}

It is important to note that the above figures are just numerical. The linguistic profile of King Abdullah of Jordan refers to his British and US educational background, since he graduated from Pembroke College, Staff College, Camberley, St Edmund's School, Edmund A. Walsh School of Foreign Service (Washington), Deerfield Academy (Massachusetts), and Eaglebrook School (Massachusetts). His wife Queen Rania also has a US educational background, having obtained her BA from the AUC, Egypt. Both received training in Arabic since infancy, so they are bilinguals. Naguib Sawiris, on the other hand, did not receive early education in English nor did he obtain any higher degree in the English language. He was educated at ETH Zurich, Switzerland, and Deutsche Evangelische Oberschule, a German school in Dokki, Giza, Egypt. He speaks 
English occasionally. Likewise, Tzipi Livni did not receive any early training in English nor did she obtain any higher degree in the English language. She graduated from Ironi Alef High School and Bar-Ilan University, both in Israel. She speaks English with a heavy foreign accent.

Another significant point is the size of the present corpora. The size of the corpora might seem small, yet the new variables (namely, orality and nativeness) they introduce make them stand as a sizable sample to yield valuable insights. Compared to Kibrik's (1999) English corpus, which included around 14,000 words, the present sample is made up of 9968 words. The added value of the present selections is that they represent different spontaneous texts, produced orally at varying proficiency levels, while Kibrik used one written text in English, taken from a children's story. Thus, the present corpora can be considered sizable if viewed within the framework of their production medium, being primarily oral, and proficiency.

The sizes of the two corpora, in terms of duration and number of words, are summarized in the following table:

Table 3: A summary of the corpora selected

\begin{tabular}{|l|l|l|l|}
\hline Speech/Speaker & Nativeness & Duration (ms:secs) & Number of Words \\
\hline Barack Obama & Native & $8: 52$ & 859 \\
\hline King Abdullah & Near-Native & $9: 17$ & 941 \\
\hline Naguib Sawiris & Non-Native & $8: 11$ & 1421 \\
\hline Jacinda Ardern & Native & $22: 04$ & 2621 \\
\hline Queen Rania & Near-Native & $13: 58$ & 2126 \\
\hline Tzipi Livni & Non-Native & $16: 11$ & 2000 \\
\hline Total & & $1: 15$ hours & 9968 \\
\hline
\end{tabular}

\subsection{Methodology and tools}

Two methods were used for each corpus. The first method is the manual analysis of the referential choices according to the model proposed above under Section 3. This includes dividing the texts in question into clauses and detecting coreferences 
as accurately as possible. Values are also assigned to the anaphors and their antecedents according to Kibrik's (1999) model. The second method is electronic, where the Huggingface online software is used to reconcile the results obtained by the manual analysis and debug dubious cases of referentiality. Moreover, the voice print and frequency levels, particularly F0, are obtained via Praat 6 for Windows. Then, the FAS is calculated based on the results obtained both manually and electronically to achieve a valid picture of referential choices in each text/discourse.

It is of note that the procedures of analysis are geared towards discovering the ways in which native, near-native and non-native discourse cohere by dint of referential choices. Therefore, the analysis commences with the native speakers' discourse down to the non-native one as is shown in Section 5 below. Then, a comparison among the three discourses is held to show similarities and differences.

\section{Analysis}

\subsection{Analysis of Referential Choices in Native Speakers' Discourse}

In this section, the referential choices in Barack Obama's and Jacinda Ardern's discourses are analyzed according to the modified version of Kibrik's (1999) model.

\subsubsection{Barack Obama's Discourse:}

The following table provides a comprehensive picture of the frequencies of referential choice and their values in addition to the FAS in Barack Obama's discourse:

Table 4: The frequencies of referential choice and their values in addition to the FAS in Barack Obama's discourse

\begin{tabular}{|c|c|c|c|c|c|}
\hline \multirow[t]{2}{*}{$\begin{array}{l}\text { L } \\
\text { REFERENT } \\
\text { IAL }\end{array}$} & $\begin{array}{l}\text { FULL NP } \\
\text { ONLY }\end{array}$ & $\begin{array}{l}\text { FULL NP? } \\
\text { PRONOUN }\end{array}$ & $\begin{array}{l}\text { FULL NP } \\
\text { OR } \\
\text { PRONOU } \\
\mathrm{N}\end{array}$ & $\begin{array}{l}\text { PRONOUN } \\
\text { ? NP }\end{array}$ & $\begin{array}{l}\text { PRONOUN } \\
\text { ONLY }\end{array}$ \\
\hline & Identical / & Identical & Identical / & Identical & Identical \\
\hline
\end{tabular}


REFERENTIAL CHOICE IN THE DISCOURSE OF NATIVE, NEAR-NATIVE AND NON-NATIVE SPEAKERS OF ENGLISH: REVISITING KIBRIK'S APPROACH

\begin{tabular}{|c|c|c|c|c|c|c|c|c|c|c|c|c|c|c|c|c|c|}
\hline uency level & $\begin{array}{l}\text { Close / } \\
\text { Approxim } \\
\text { ate/ } \\
\text { Different / } \\
\text { Completel } \\
\text { y different } \\
\text { frequency }\end{array}$ & \multicolumn{3}{|c|}{$\begin{array}{l}\text { Close / } \\
\text { Approximat } \\
\text { e/ Different } \\
\text { / } \\
\text { Completely } \\
\text { different } \\
\text { frequency }\end{array}$} & \multicolumn{4}{|c|}{\begin{tabular}{|l|} 
Close / \\
Approxima \\
te/ \\
Different / \\
Completely \\
different \\
frequency
\end{tabular}} & \multicolumn{4}{|c|}{$\begin{array}{l}\text { Close } \\
\text { Approximat } \\
\text { e/ Different } \\
\text { / } \\
\text { Completely } \\
\text { different } \\
\text { frequency }\end{array}$} & \multicolumn{5}{|c|}{$\begin{array}{l}\text { Close / } \\
\text { Approximate/ } \\
\text { Different / } \\
\text { Completely } \\
\text { different } \\
\text { frequency }\end{array}$} \\
\hline F0 Range & $\begin{array}{l}\text { 133.1- } \\
151.4 \mathrm{~Hz}\end{array}$ & \multicolumn{3}{|c|}{0} & \multicolumn{4}{|c|}{0} & \multicolumn{4}{|c|}{0} & \multicolumn{5}{|c|}{$\begin{array}{l}120.2-141.5 \\
\mathrm{~Hz}\end{array}$} \\
\hline \multirow[t]{2}{*}{ Occurrences } & \begin{tabular}{l|l|l|l|}
0 & 0 & 2 & 0 \\
\end{tabular} & \begin{tabular}{l|l|}
6 & 0
\end{tabular} & \begin{tabular}{l|l}
0 & 0
\end{tabular} & 0 & 00 & 0 & 0 & 0 & 00 & 0 & \begin{tabular}{l|l}
0 \\
\end{tabular} & 0 & 0 & 0 & $\begin{array}{l}2 \\
8\end{array}$ & & \\
\hline & Total: 8 & \multicolumn{3}{|c|}{ Total: 0} & \multicolumn{4}{|c|}{ Total: 0} & \multicolumn{4}{|c|}{ Total: 0} & \multicolumn{5}{|c|}{ Total: 80} \\
\hline $\begin{array}{l}\text { Full } \\
\text { Activation } \\
\text { Score (FAS) }\end{array}$ & $0-0.2$ & \multicolumn{3}{|l|}{0} & \multicolumn{4}{|c|}{ U } & \multicolumn{4}{|l|}{0} & \multicolumn{5}{|c|}{$7.98^{2}$} \\
\hline
\end{tabular}

Before commenting on the above table, it is noteworthy to add one segment form the PRONOUN ONLY category has been debugged by Huggingface to ensure consistent coreferentiality. The figure below illustrates that:

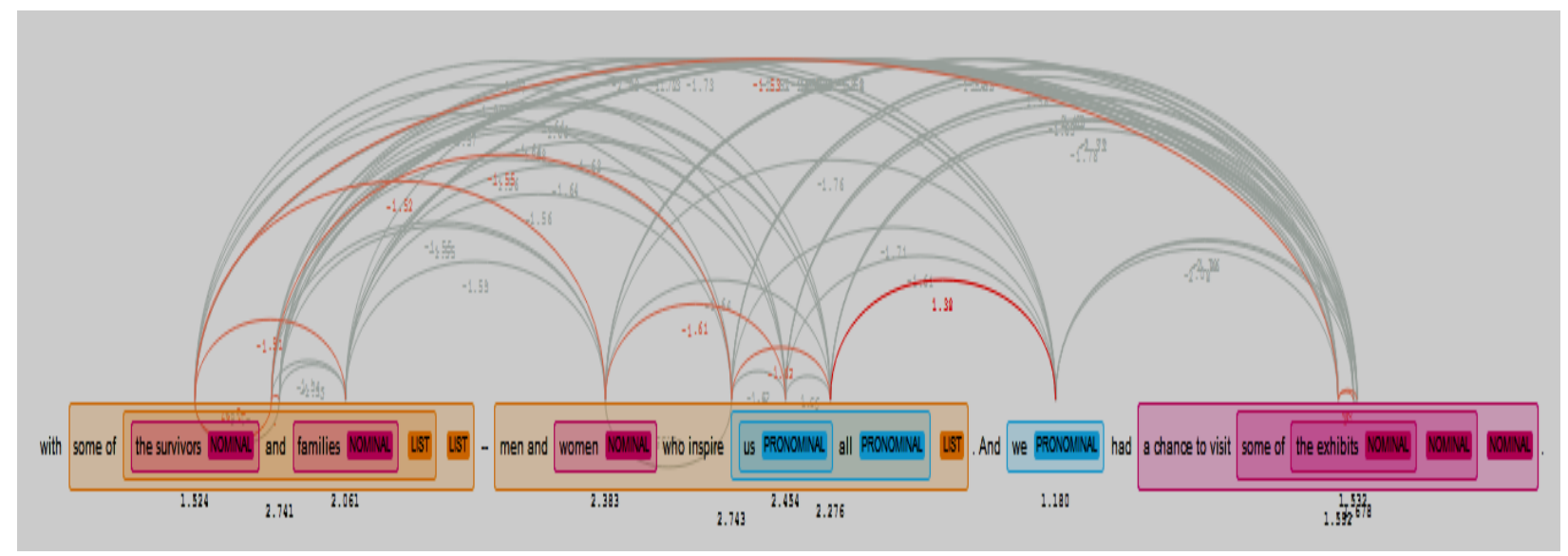

Fig.3 Debugging one dubious case in Obama's discourse via Huggingface

\footnotetext{
${ }^{2}$ One case was debugged by Huggingface. 
The result of this debugging is that the pronoun 'we' is correctly assigned to its appropriate coreference 'us' in the same discoursal span.

It is clear from the above table that Obama's discourse is marked by a tendency to situate referential choices at the two extremes of the potential reference and the FAS. This causes his speech to be based on cataphora more than anaphora, since in most cases, he mentions the pronoun first then inserts the reference later in his discourse. Although this rhetorical strategy renders his discourse interesting and lively, it negatively impinges on the F0 levels: the occurrences of approximate and (completely) different frequency levels are increased, since the progression of discourse is similar to forgetting in terms of memory operations. This can be better viewed within the framework of the Obama's voiceprint as detected by Praat's pitch-dependent analysis. The following table gives the obtained data as the voiceprint of his text:

Table 5: Barack Obama's voiceprint as detected by Praat's pitch-dependent analysis

\begin{tabular}{|l|l|}
\hline Features & Values \\
\hline 1. Frequency domain: & 0 \\
\hline Lowest frequency: Hz & $9001 \mathrm{~Hz}$ \\
\hline Highest Frequency: & $22050 \mathrm{~Hz}$ \\
\hline Total bandwidth: & 439 \\
\hline 2. Frequency sampling: & $50 \mathrm{~Hz}$ \\
\hline Number of frequency bands (bins): & $100 \mathrm{~Hz}$ \\
\hline Frequency step (bin width): & \\
\hline $\begin{array}{l}\text { First frequency band around (bin } \\
\text { centre at): }\end{array}$
\end{tabular}

The above table is informative, since it can be utilized to achieve a relative calculation of the values obtained for the potential referential form as compared to the F0 levels. In other words, the relativeness of the occurrences of the referential form can be set vis-à-vis the relativeness of F0 to the highest frequency of the voiceprint. If calculated this way, it turns out that in terms of referential form 
frequency (i.e. occurrences), the for both full NP only and pronouns only, the occurrences of approximate and (completely) different frequencies amount to $1.51 \%$. This is similar to the highest $\mathrm{F} 0$, which is $151.4 \mathrm{~Hz}$, as compared with the highest frequency of the voiceprint. The relative result is $1.68 \%$. The similarity in the two percentiles refers to the consistency of the discourse progression as to the potential referential forms and the F0: Obama's text is uniform in that it preserves the unusual structure of referentiality as situated on the two extremes of full NP and pronouns only. Again, this is largely attributable to the dependence on cataphora as a valid rhetorical device, and cannot be considered as a sign of forgetting.

\subsubsection{Analysis of Jacinda Ardern's Discourse:}

The following table provides a comprehensive picture of the frequencies of referential choice and their values in addition to the FAS in Jacinda Ardern's discourse:

Table 6: The frequencies of referential choice and their values in addition to the FAS in Jacinda Ardern's discourse

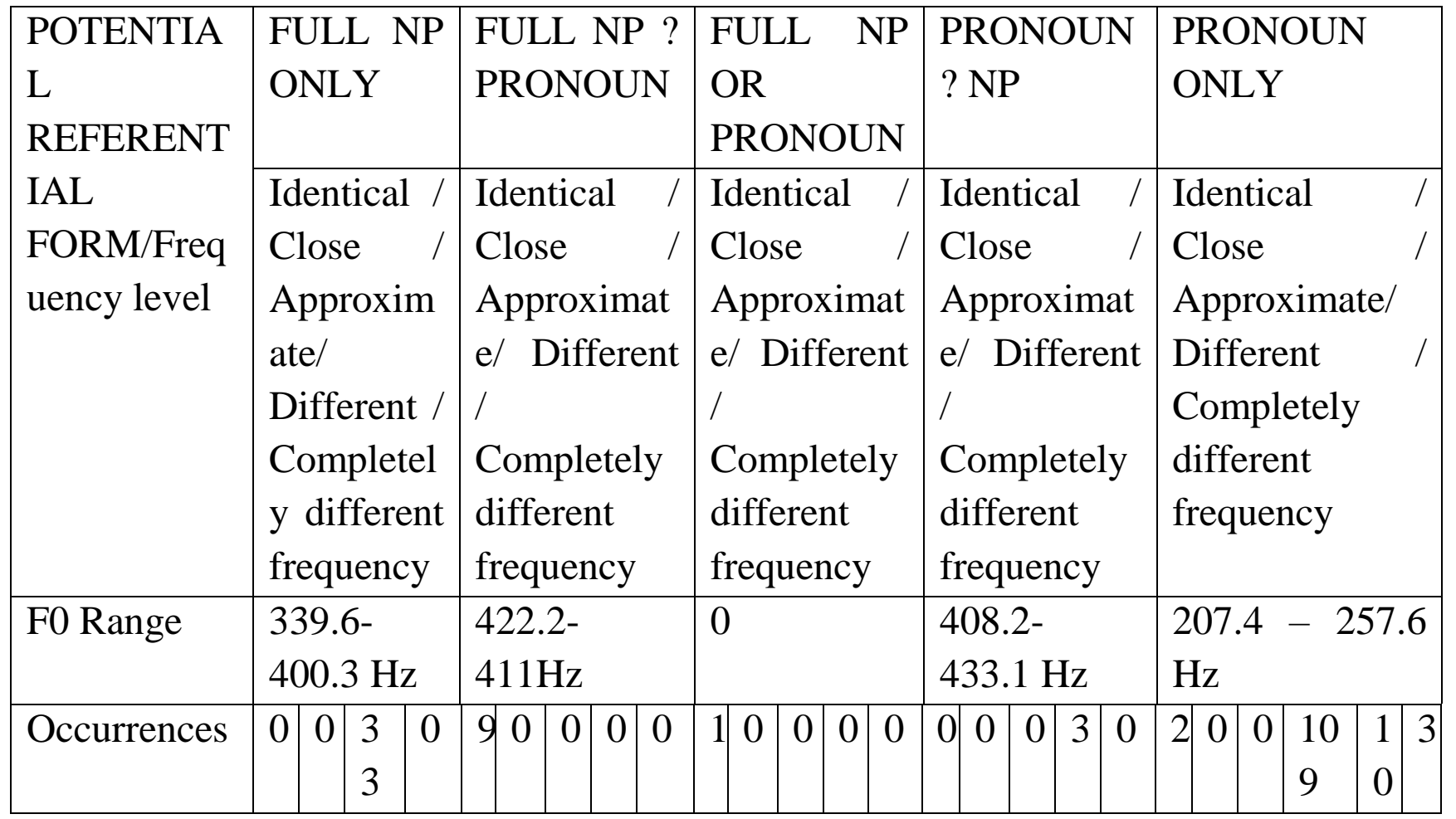


REFERENTIAL CHOICE IN THE DISCOURSE OF NATIVE, NEAR-NATIVE AND

NON-NATIVE SPEAKERS OF ENGLISH: REVISITING KIBRIK'S APPROACH

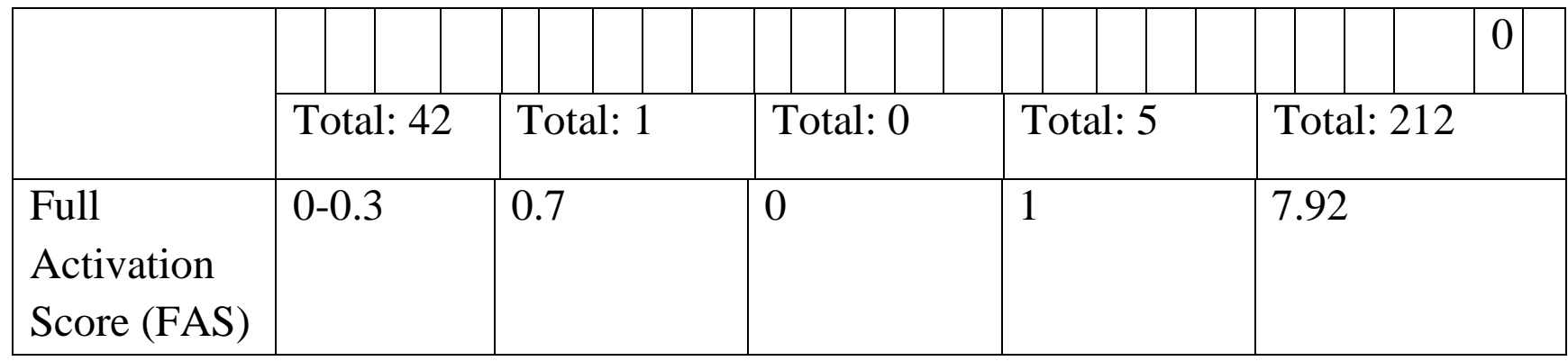

It is clear from the above table that Ardern's discourse is marked by a tendency to strike a balance between the different stages of referential choices. This causes her speech to be based on consistent coreferences, since in most cases, she mentions the full NP first then inserts the reference just in place after that in her discourse. This pattern renders her text highly cohesive, and it positively impinges on the F0 levels: the occurrences of approximate and (completely) different frequency levels are highly consistent, since the progression of discourse is similar to both capacity and control in terms of the WM operations. This can be better viewed within the framework of the Ardern's voiceprint as detected by Praat's pitch-dependent analysis. The following table gives the obtained data as the voiceprint of her text:

Table 7: Jacinda Ardern's voiceprint as detected by Praat's pitch-dependent analysis

\begin{tabular}{|l|l|}
\hline Features & Values \\
\hline 1. Frequency domain: & 0 \\
\hline Lowest frequency: Hz & $4866 \mathrm{~Hz}$ \\
\hline Highest Frequency: & $22050 \mathrm{~Hz}$ \\
\hline Total bandwidth: & 439 \\
\hline 2. Frequency sampling: & $50 \mathrm{~Hz}$ \\
\hline Number of frequency bands (bins): & $100 \mathrm{~Hz}$ \\
\hline $\begin{array}{l}\text { Frequency step (bin width): } \\
\text { First frequency band around (bin } \\
\text { centre at): }\end{array}$ & \\
\hline
\end{tabular}


The above table is informative, since it can be utilized to achieve a relative calculation of the values obtained for the potential referential form as compared to the F0 levels. In other words, the relativeness of the occurrences of the referential form can be set vis-à-vis the relativeness of F0 to the highest frequency of the voiceprint. If calculated this way, it turns out that in terms of referential form frequency (i.e. occurrences), the full NP, the occurrences of approximate and (completely) different frequencies amount to $8.23 \%$. This is not similar to the value of the pronoun only, which is $5.32 \%$, but close to FULL NP ? PRONOUN and PRONOUN ? NP, which are $8.41 \%$ and $8.86 \%$, respectively. The similarity in the two percentiles refers to the consistency of the discourse progression as to the potential referential forms and the F0: Arden's text is uniform in that it preserves the unusual structure of referentiality as situated on the three stages. Yet the FULL NP OR PRONOUN is missing due to the high degree of cohesiveness of the discourse by dint of keeping a consistent pattern of referentiality that does not allow referential redundancy.

\subsection{Analysis of Referential Choices in Near-Native Speakers' Discourse}

\subsubsection{Analysis of King Abdullah's Discourse:}

The following table provides a comprehensive picture of the frequencies of referential choice and their values in addition to the FAS in King Abdullah's discourse:

Table 8: The frequencies of referential choice and their values in addition to the FAS in King Abdullah's discourse

\begin{tabular}{|c|c|c|c|c|c|}
\hline \multirow{4}{*}{$\begin{array}{l}\text { POTENTIA } \\
\text { L } \\
\text { REFERENT } \\
\text { IAL } \\
\text { FORM/Freq } \\
\text { uency level }\end{array}$} & $\begin{array}{l}\text { FULL NP } \\
\text { ONLY }\end{array}$ & $\begin{array}{l}\text { FULL NP ? } \\
\text { PRONOUN }\end{array}$ & $\begin{array}{l}\text { FULL NP } \\
\text { OR } \\
\text { PRONOUN }\end{array}$ & $\begin{array}{l}\text { PRONOUN } \\
\text { ? NP }\end{array}$ & $\begin{array}{l}\text { PRONOUN } \\
\text { ONLY }\end{array}$ \\
\hline & Identical / & entical / & Identical / & cal & Identical \\
\hline & Close & Close & Close & Close $\quad /$ & Close \\
\hline & $\begin{array}{l}\text { Approxim } \\
\text { ate/ } \\
\text { Different / } \\
\text { Completel }\end{array}$ & $\begin{array}{l}\text { Approximat } \\
\text { e/ Different } \\
\text { / } \\
\text { Completely }\end{array}$ & $\begin{array}{l}\text { Approximat } \\
\text { e/ Different } \\
\text { / } \\
\text { Completely }\end{array}$ & $\begin{array}{l}\text { Approximat } \\
\text { e/ Different } \\
\text { / } \\
\text { Completely }\end{array}$ & $\begin{array}{l}\text { Approximate/ } \\
\text { Different / } \\
\text { Completely } \\
\text { different }\end{array}$ \\
\hline
\end{tabular}


REFERENTIAL CHOICE IN THE DISCOURSE OF NATIVE, NEAR-NATIVE AND NON-NATIVE SPEAKERS OF ENGLISH: REVISITING KIBRIK'S APPROACH

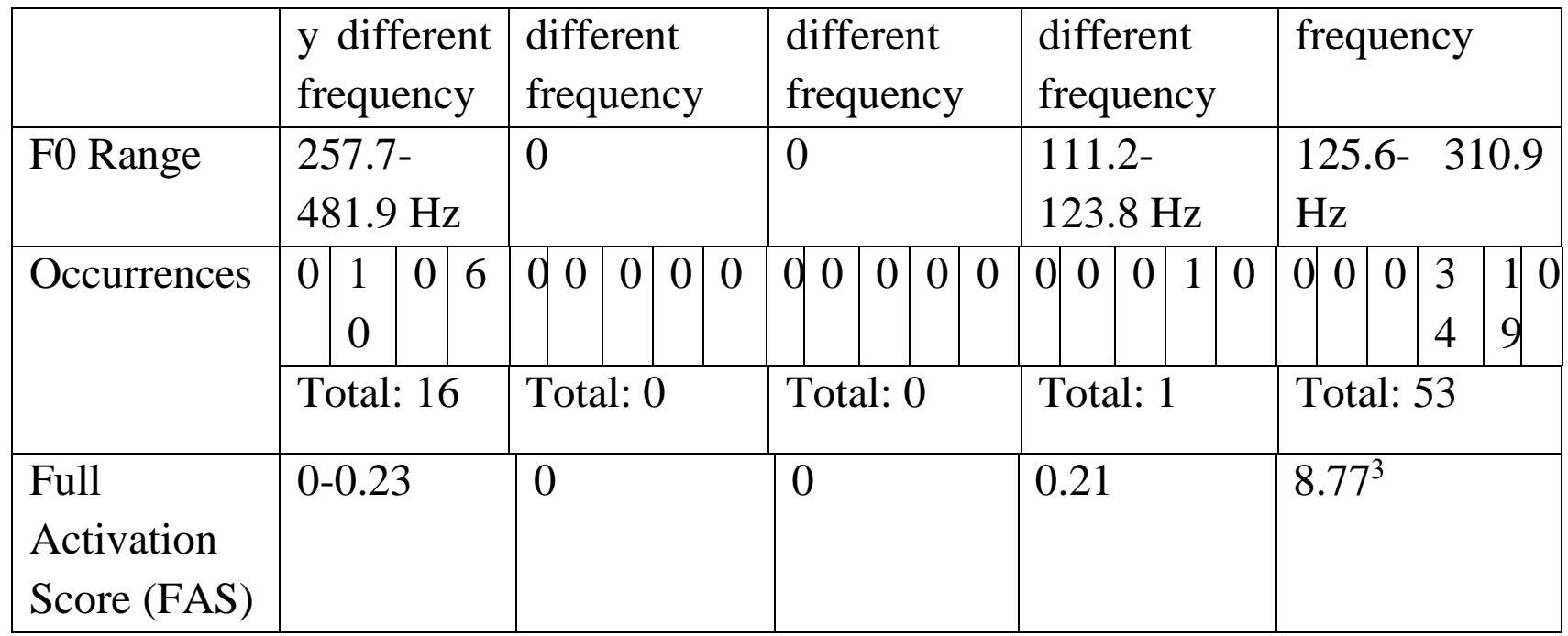

Before commenting on the above table, it is noteworthy to add one segment form the PRONOUN ONLY category has been debugged by Huggingface to ensure consistent coreferentiality. The figure below illustrates that:

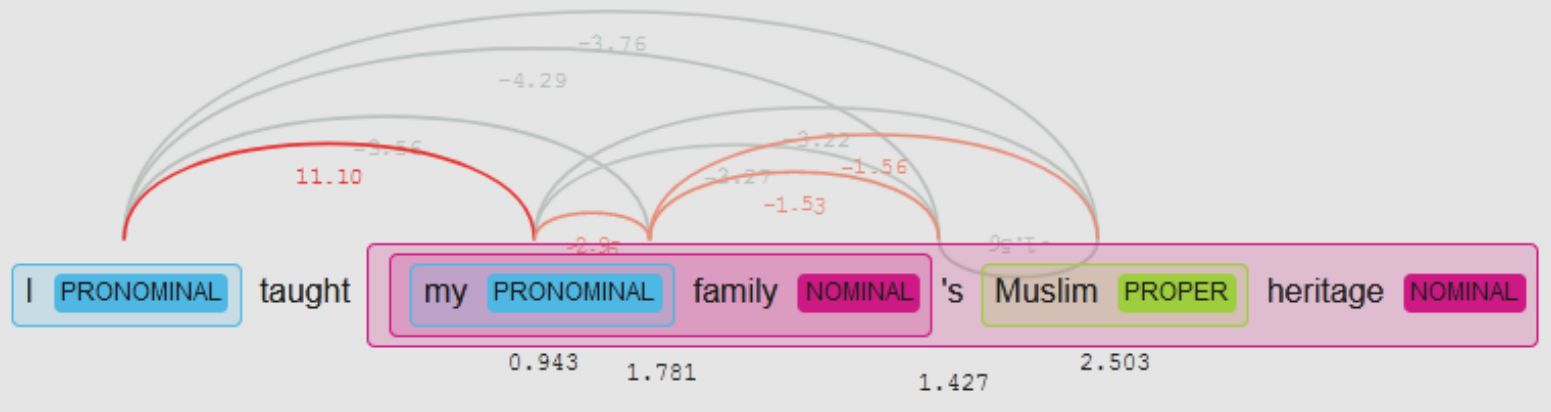

Fig.4 Debugging one dubious case in King Abdullah's discourse via Huggingface The result of this debugging is that the pronoun ' $\mathrm{I}$ ' is correctly assigned to its appropriate coreference 'my' in the same discoursal span.

\footnotetext{
${ }^{3}$ Reconciled by Huggingface.
} 


\section{REFERENTIAL CHOICE IN THE DISCOURSE OF NATIVE, NEAR-NATIVE AND NON-NATIVE SPEAKERS OF ENGLISH: REVISITING KIBRIK'S APPROACH}

It is clear from the above table that King Abdullah's discourse is distinguished by focusing on three stages of referential choice. This causes his speech to be based on somewhat consistent coreferences, since in most cases, he mentions some full NPs first then inserts the reference, in most cases, just in place but not directly after that in her discourse. This pattern renders her text cohesive, and it positively impinges on the F0 levels: the occurrences of approximate and (completely) different frequency levels are highly consistent, since the progression of discourse is similar to capacity in terms of the WM operations. This can be better viewed within the framework of the King Abdullah's voiceprint as detected by Praat's pitch-dependent analysis. The following table gives the obtained data as the voiceprint of his text:

Table 9: King Abdullah's voiceprint as detected by Praat's pitch-dependent analysis

\begin{tabular}{|c|c|}
\hline Features & Values \\
\hline \multicolumn{2}{|l|}{ 1. Frequency domain: } \\
\hline Lowest frequency: $\mathrm{Hz}$ & 0 \\
\hline Highest Frequency: & $4036 \mathrm{~Hz}$ \\
\hline Total bandwidth: & $22050 \mathrm{~Hz}$ \\
\hline \multicolumn{2}{|l|}{ 2. Frequency sampling: } \\
\hline Number of frequency bands (bins): & 439 \\
\hline Frequency step (bin width): & $50 \mathrm{~Hz}$ \\
\hline $\begin{array}{l}\text { First frequency band around (bin } \\
\text { centre at): }\end{array}$ & $100 \mathrm{~Hz}$ \\
\hline
\end{tabular}

The above table is informative, since it can be utilized to achieve a relative calculation of the values obtained for the potential referential form as compared to the F0 levels. In other words, the relativeness of the occurrences of the referential form can be set vis-à-vis the relativeness of F0 to the highest frequency of the voiceprint. If calculated this way, it turns out that in terms of referential form frequency (i.e. occurrences), the full NP, the occurrences of approximate and 
(completely) different frequencies amount to $11.94 \%$. This is not similar to the value of the pronoun only, which is $7.77 \%$, but completely different from that of PRONOUN ? NP, which is $0.025 \%$. The divergence in the two percentiles refers to the relative inconsistency of the discourse progression as to the potential referential forms and the F0: King Abdullah's text is uniform in that it preserves the almost cohesive structure of referentiality as situated on the three stages. Yet the FULL NP OR PRONOUN is missing due to cohesiveness of the discourse by dint of keeping a consistent pattern of referentiality that does not allow referential redundancy.

\subsubsection{Analysis of Queen Rania's Discourse:}

The following table provides a comprehensive picture of the frequencies of referential choice and their values in addition to the FAS in Queen Rania's discourse:

Table 10: the frequencies of referential choice and their values in addition to the FAS in Queen Rania's discourse

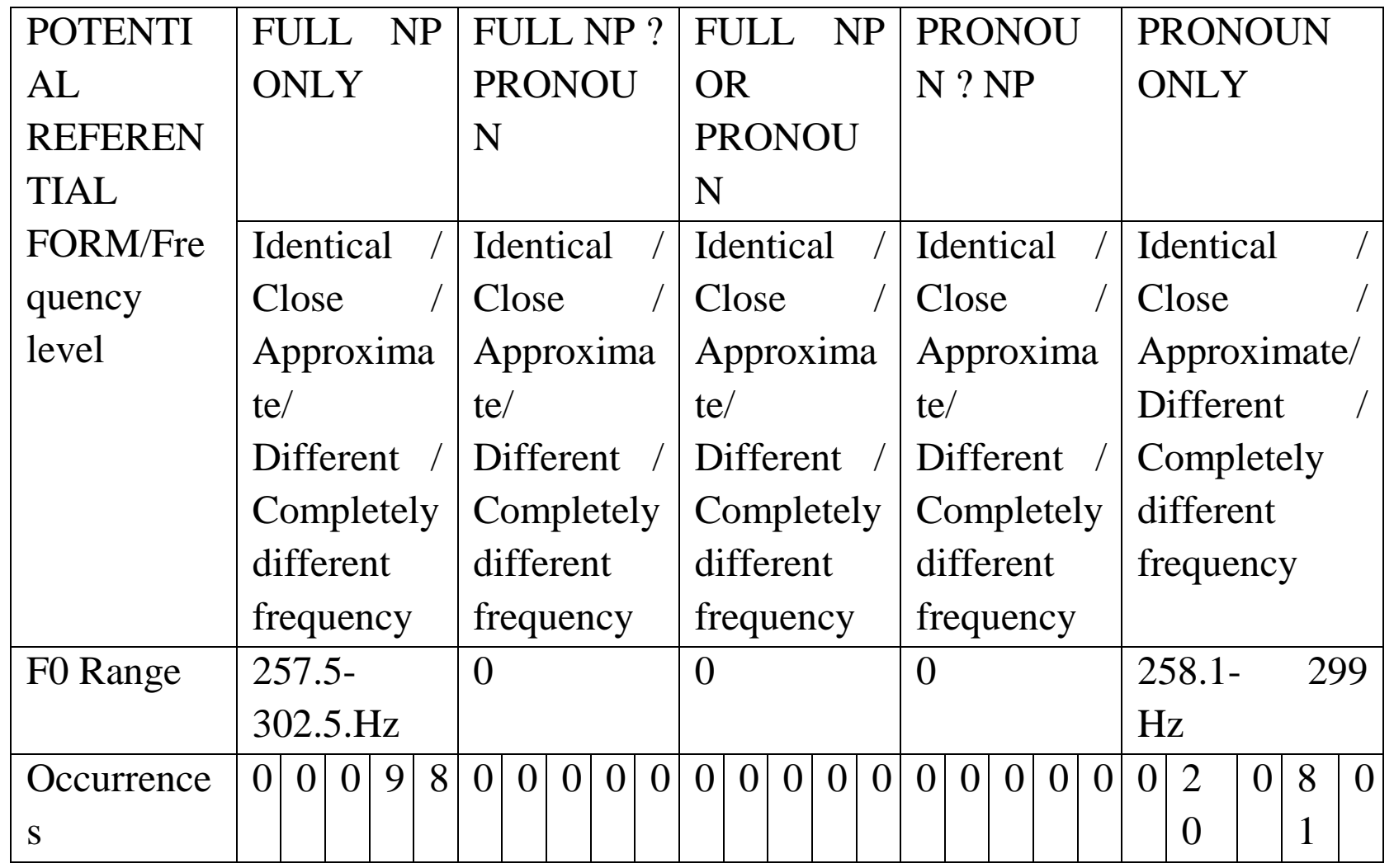


REFERENTIAL CHOICE IN THE DISCOURSE OF NATIVE, NEAR-NATIVE AND

NON-NATIVE SPEAKERS OF ENGLISH: REVISITING KIBRIK'S APPROACH

\begin{tabular}{|c|c|c|c|c|c|}
\hline & & & & & 1 \\
\hline & Total: 17 & Total: 0 & Total: 0 & Total: 0 & Total: 282 \\
\hline $\begin{array}{l}\text { Full } \\
\text { Activation } \\
\text { Score } \\
\text { (FAS) }\end{array}$ & $0-0.22$ & 0 & 0 & 0 & $10.88^{4}$ \\
\hline
\end{tabular}

Before commenting on the above table, it is noteworthy to add one segment form the PRONOUN ONLY category has been debugged by Huggingface to ensure consistent coreferentiality. The figure below illustrates that:

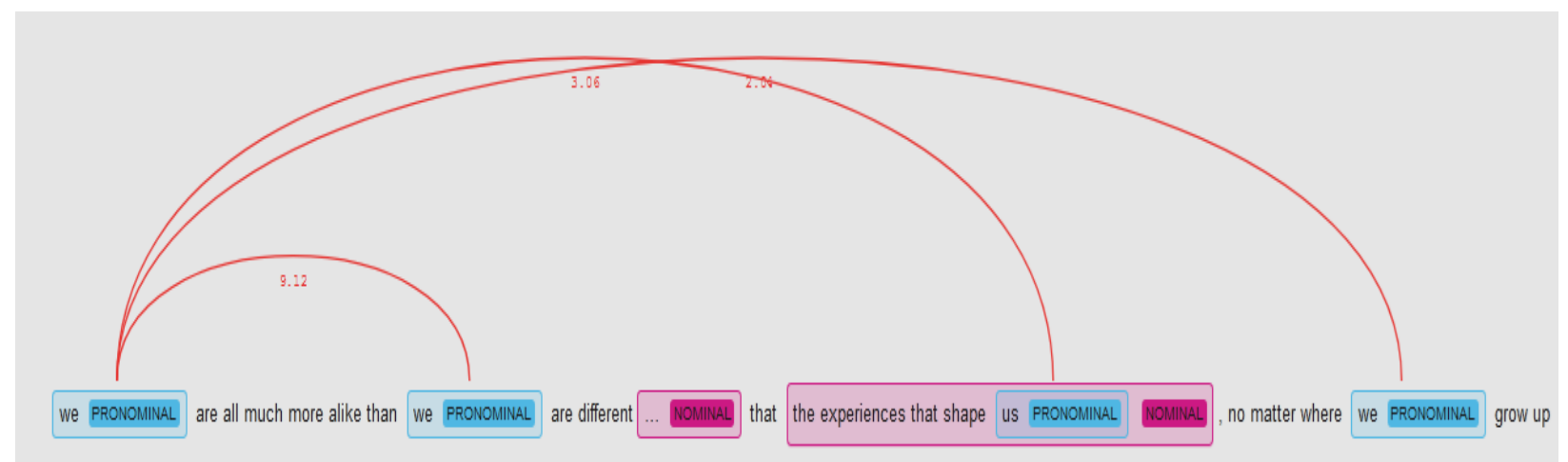

Fig.5 Debugging one dubious case in Queen Rania’s discourse via Huggingface

The pronoun 'we' is consistently assigned to its anaphora in the illustrated span.

It is clear from the above table that Queen Rania's discourse is restricted to two stages only of referential choice. This causes his speech to be based on somewhat consistent coreferences, since in most cases, she mentions some full NPs first then inserts the reference, in most cases, just in place but not directly after that in her discourse, leaving no space for dubious FULL NP ? PRONOUN and PRONOUN ? NP. This pattern renders her text cohesive, yet it sometimes negatively impinges on the F0 levels for Full NP: the occurrences of (completely) different frequency

\footnotetext{
${ }^{4}$ Some results were debugged by Huggingface. 
levels dominate her text; this progression of discourse is similar to capacity in terms of the WM operations. This can be better viewed within the framework of Queen Rania's voiceprint as detected by Praat's pitch-dependent analysis. The following table gives the obtained data as the voiceprint of her text:

Table 11: Queen Rania's voiceprint as detected by Praat's pitch-dependent analysis

\begin{tabular}{|l|l|}
\hline Features & Values \\
\hline 1. Frequency domain: & 0 \\
\hline Lowest frequency: Hz & $3052 \mathrm{~Hz}$ \\
\hline Highest Frequency: & $22050 \mathrm{~Hz}$ \\
\hline Total bandwidth: & 439 \\
\hline 2. Frequency sampling: & $50 \mathrm{~Hz}$ \\
\hline Number of frequency bands (bins): & $100 \mathrm{~Hz}$ \\
\hline $\begin{array}{l}\text { Frequency step (bin width): } \\
\text { First frequency band around (bin } \\
\text { centre at): }\end{array}$ & \\
\hline
\end{tabular}

The above table is informative, since it can be utilized to achieve a relative calculation of the values obtained for the potential referential form as compared to the F0 levels. In other words, the relativeness of the occurrences of the referential form can be set vis-à-vis the relativeness of F0 to the highest frequency of the voiceprint. If calculated this way, it turns out that in terms of referential form frequency (i.e. occurrences), the full NP, and the occurrences of (completely) different frequencies amount to $10 \%$. This is close to the value of the pronoun only, which is $9.79 \%$. The convergence in the two percentiles refers to the relative consistency of the discourse progression as to the potential referential forms and the F0: Queen Rania's text is uniform in that it preserves the almost cohesive structure of referentiality as situated on the two stages. Yet the FULL NP OR PRONOUN is missing due to cohesiveness of the discourse by dint of keeping a consistent pattern of referentiality that does not allow referential redundancy. 


\subsection{Analysis of Referential Choices in Non-Native Speakers' Discourse}

In this section, the referential choices in Naguib Sawiris's and Tzipi Livni's discourses are analyzed according to the methodology adopted in the present study.

\subsubsection{Analysis of Naguib Sawiris's Discourse:}

The following table provides a comprehensive picture of the frequencies of referential choice and their values in addition to the FAS in Naguib Sawiris's discourse:

Table 12: The frequencies of referential choice and their values in addition to the FAS in Naguib Sawiris's discourse

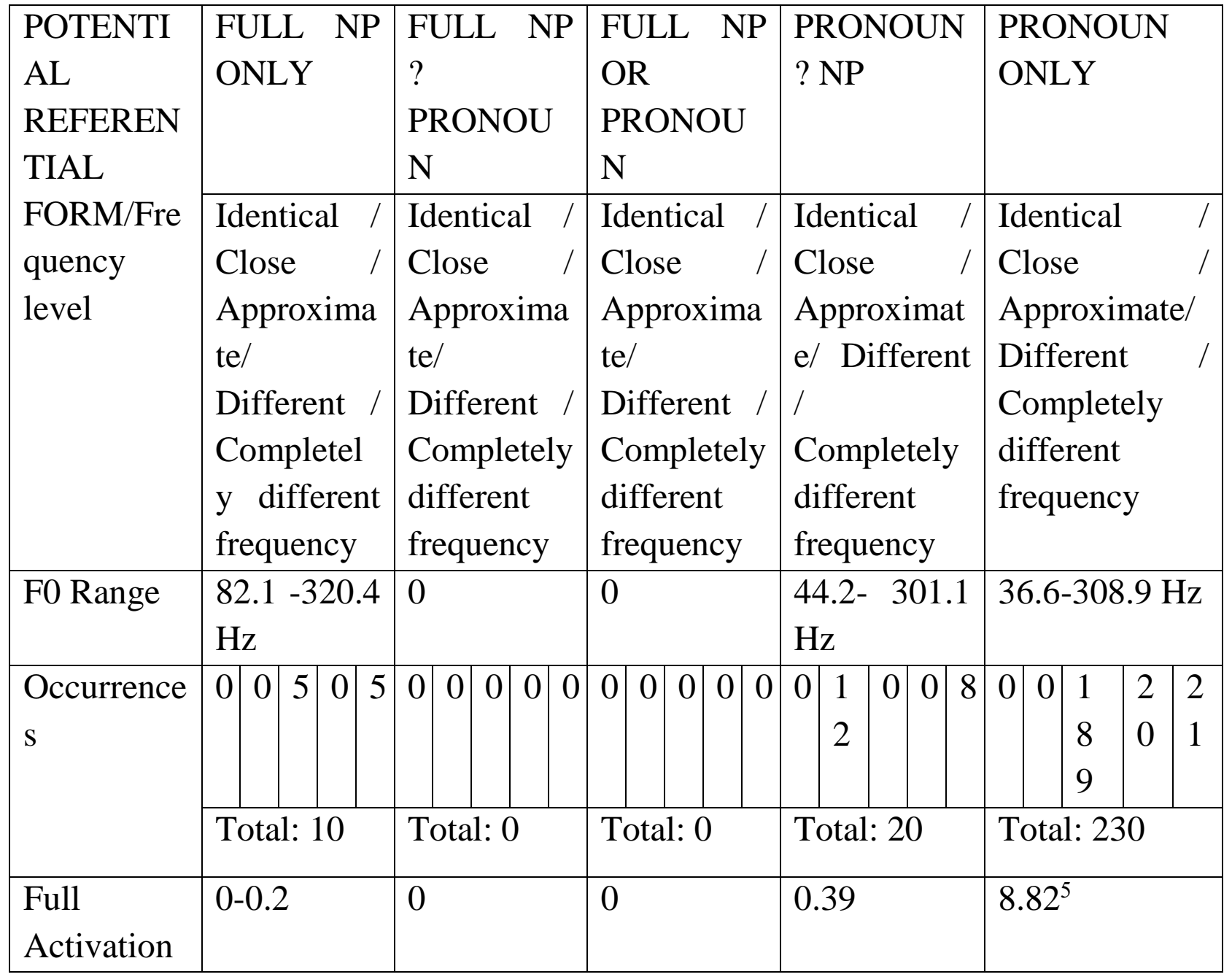

\footnotetext{
${ }^{5}$ One case was debugged by Huggingface. 
Score (FAS)

Before commenting on the above table, it is noteworthy to add one segment form the PRONOUN ONLY category has been debugged by Huggingface to ensure consistent coreferentiality. The figure below illustrates that:

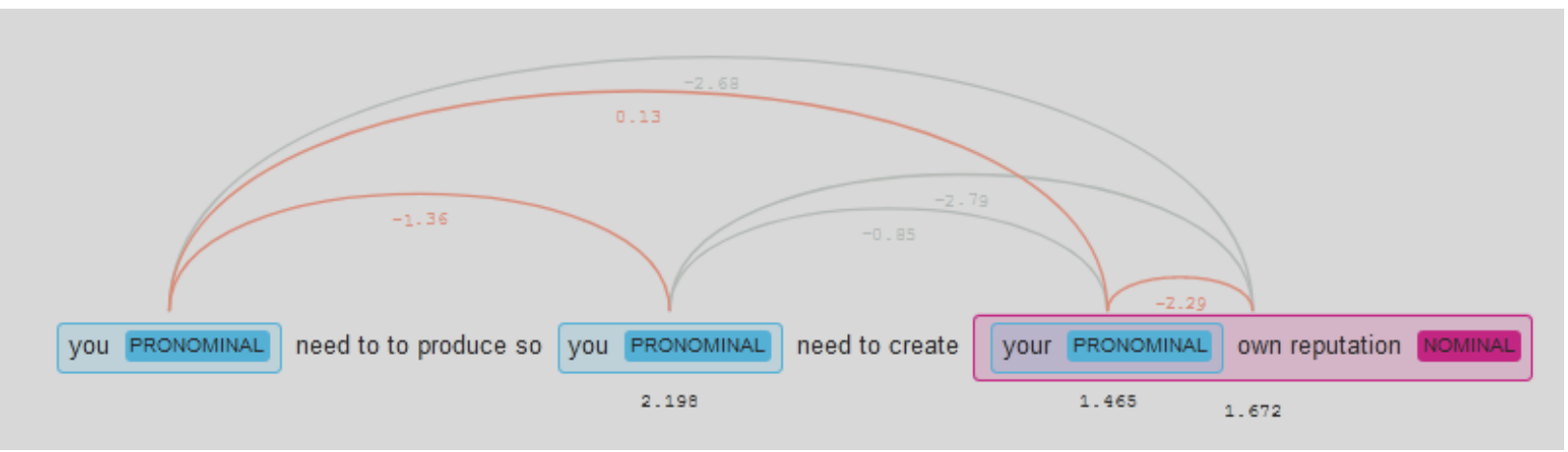

Fig.6 Debugging one dubious case in Sawiris's discourse via Huggingface

The debugging exhibits that the pronoun 'you' is correctly and consistently assigned to its anaphora 'your' in this discoursal span.

It is clear from the above table that Naguib Sawiris's discourse utilizes three stages of referential choice. Despite the fact that he is consistent in his coreferences, he sparingly mentions full NPs. He omits to use both FULL NP ? PRONOUN and FULL NP OR PRONOUN. This negatively impinges on the coherence of the discourse, but this imbalance is redressed by using PRONOUN ? NP. Yet the text appears to be cohesive, being full of the PRONOUN ONLY category. This cohesiveness does tally with the F0 levels for Full NP: the occurrences of approximate frequency levels dominate the text; this progression of discourse is similar to control in terms of the WM operations. This can be better viewed within the framework of Naguib Sawiris's voiceprint as detected by Praat's pitchdependent analysis. The following table gives the obtained data as the voiceprint of her text:

Table 13: Naguib Sawiris's voiceprint as detected by Praat's pitch-dependent analysis 
REFERENTIAL CHOICE IN THE DISCOURSE OF NATIVE, NEAR-NATIVE AND

NON-NATIVE SPEAKERS OF ENGLISH: REVISITING KIBRIK'S APPROACH

\begin{tabular}{|c|c|}
\hline Features & Values \\
\hline \multicolumn{2}{|l|}{ 1. Frequency domain: } \\
\hline Lowest frequency: $\mathrm{Hz}$ & $36.58 \mathrm{~Hz}$ \\
\hline Highest Frequency: & $4451 \mathrm{~Hz}$ \\
\hline Total bandwidth: & $22050 \mathrm{~Hz}$ \\
\hline \multicolumn{2}{|l|}{ 2. Frequency sampling: } \\
\hline Number of frequency bands (bins): & 439 \\
\hline Frequency step (bin width): & $50 \mathrm{~Hz}$ \\
\hline $\begin{array}{l}\text { First frequency band around (bin } \\
\text { centre at): }\end{array}$ & $100 \mathrm{~Hz}$ \\
\hline
\end{tabular}

According to the above table, the relativeness of the occurrences of the referential form can be set vis-à-vis the relativeness of F0 to the highest frequency of the voiceprint. If calculated this way, it turns out that in terms of referential form frequency (i.e. occurrences), the full NP and the occurrences of (completely) different frequencies amount to $7.20 \%$. This is slightly closer to the value of the pronoun only, which is $6.94 \%$. However, the approximate occurrences of the referential form assume a higher profile in the discourse in question: the percentages are $7.20 \%, 6.76 \%$ and $6.94 \%$ for FULL NP, PRONOUN ? NP, and PRONOUN ONLY, respectively. These percentiles refer to the relative consistency of the discourse progression as to the potential referential forms and the F0: Naguib Sawiris's text is uniform in that it preserves the almost cohesive structure of referentiality as situated on the three stages. Yet both FULL NP ? PRONOUN and FULL NP OR PRONOUN are missing: this may be due to keeping a consistent pattern of referentiality that does not allow referential redundancy.

\subsubsection{Analysis of Tzipi Livni’s Discourse}

The following table provides a comprehensive picture of the frequencies of referential choice and their values in addition to the FAS in Tzipi Livni's discourse: 
Table 14: The frequencies of referential choice and their values in addition to the FAS in Tzipi Livni's discourse

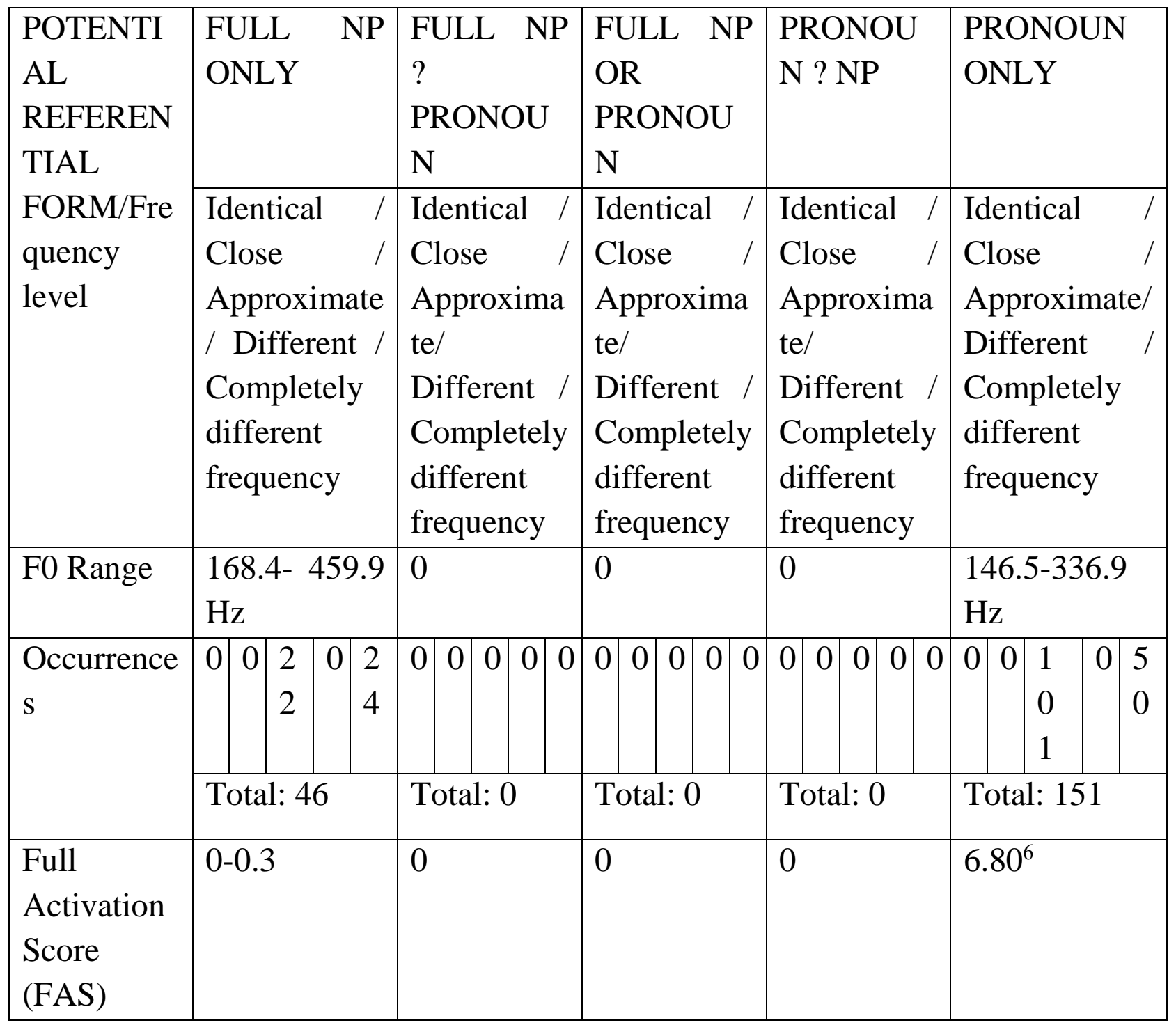

Before commenting on the above table, it is noteworthy to add one segment form the PRONOUN ONLY category has been debugged by Huggingface to ensure consistent coreferentiality. The figure below illustrates that:

\footnotetext{
${ }^{6}$ Five cases were debugged by Huggingface. 


\section{REFERENTIAL CHOICE IN THE DISCOURSE OF NATIVE, NEAR-NATIVE AND}

NON-NATIVE SPEAKERS OF ENGLISH: REVISITING KIBRIK'S APPROACH

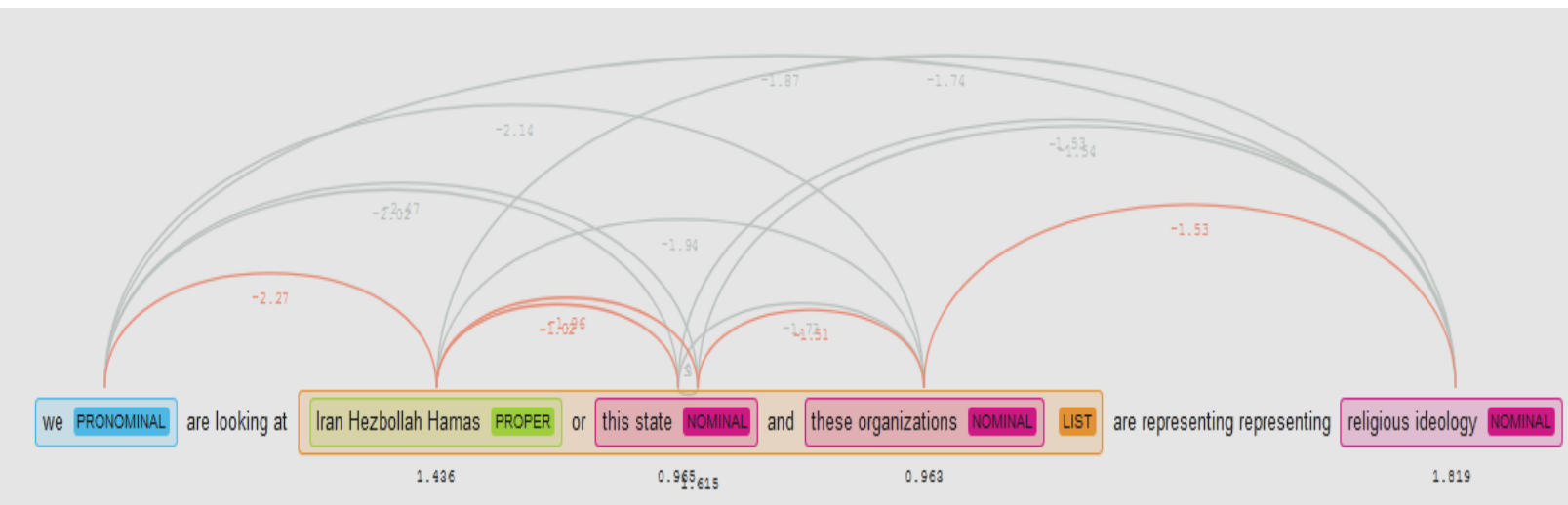

Fig.7 Debugging one dubious case in Livini's discourse via Huggingface

The debugging process shows how the pronoun 'we' and the strings 'Iran Hizbollah Hamas' are correctly assigned to their hypernym 'these organizations'.

It is clear from the above table that Tzipi Livni's discourse utilizes two stages of referential choice, i.e. it operates on the two extremes of FULL NP ONLY and PRONOUN ONLY. Despite the fact that Livni is, to a great extent, consistent in her coreferences, she omits to use FULL NP? PRONOUN and FULL NP OR PRONOUN. This negatively impinges on the coherence of the discourse, yet the text appears to be cohesive, being full of the PRONOUN ONLY category. This cohesiveness does tally with the F0 levels for Full NP: the occurrences of approximate frequency levels dominate the text; this progression of discourse is similar to capacity in terms of the WM operations. This can be better viewed within the framework of Tzipi Livni's voiceprint as detected by Praat's pitchdependent analysis. The following table gives the obtained data as the voiceprint of her text:

Table 15: Tzipi Livni's voiceprint as detected by Praat's pitch-dependent analysis

\begin{tabular}{|l|l|}
\hline Features & Values \\
\hline 1. Frequency domain: & $582.9 \mathrm{~Hz}$ \\
\hline Lowest frequency: Hz & $4910 \mathrm{~Hz}$ \\
\hline Highest Frequency: & $22050 \mathrm{~Hz}$ \\
\hline Total bandwidth: & \\
\hline 2. Frequency sampling: & \\
\hline
\end{tabular}




\begin{tabular}{|l|l|}
\hline Number of frequency bands (bins): & 439 \\
\hline Frequency step (bin width): & $50 \mathrm{~Hz}$ \\
\hline $\begin{array}{l}\text { First frequency band around (bin } \\
\text { centre at): }\end{array}$ & $100 \mathrm{~Hz}$ \\
\hline
\end{tabular}

According to the above table, the relativeness of the occurrences of the referential form can be set vis-à-vis the relativeness of F0 to the highest frequency of the voiceprint. If calculated this way, it turns out that in terms of referential form frequency (i.e. occurrences), the full NP, and the occurrences of (completely) different frequencies amount to $9.36 \%$. This is not close to the value of the pronoun only, which is $6.86 \%$. Moreover, the approximate occurrences of the referential form assume a lower profile in the discourse in question. The text is uniform in that it preserves the almost cohesive structure of referentiality as situated on the two stages. Yet the rest of the categories are missing: this may be due to keeping a consistent pattern of referentiality that does not allow referential redundancy.

\section{Comparing the Three Discourses}

A comparison among the three categories of speakers' discourse is in order. The aim of this comparison is to situate the various potential referential forms vis-à-vis the FAS with a view to corroborating or invalidating the hypothesis about the differences among the native, near- native and non-native discourse structure as explored via the criterion of referentiality. The following table summarizes the main differences among the three discourses at issue:

Table 16: A summary of the differences among the three discourses examined

\begin{tabular}{|l|l|l|l|l|l|l|}
\hline $\begin{array}{l}\text { Nativene } \\
\text { ss }\end{array}$ & Native & Native & $\begin{array}{l}\text { Near- } \\
\text { Native }\end{array}$ & $\begin{array}{l}\text { Near- } \\
\text { Native }\end{array}$ & $\begin{array}{l}\text { Non- } \\
\text { Native }\end{array}$ & $\begin{array}{l}\text { Non- } \\
\text { Native }\end{array}$ \\
\hline Text & $\begin{array}{l}\text { Barack } \\
\text { Obama's } \\
\text { Text }\end{array}$ & $\begin{array}{l}\text { Jacinda } \\
\text { Ardern's } \\
\text { Text }\end{array}$ & $\begin{array}{l}\text { King } \\
\text { Abdullah' } \\
\text { s Text }\end{array}$ & $\begin{array}{l}\text { Queen } \\
\text { Rania's } \\
\text { Text }\end{array}$ & $\begin{array}{l}\text { Naguib } \\
\text { Sawiris's } \\
\text { Text }\end{array}$ & $\begin{array}{l}\text { Tzipi } \\
\text { Livni's } \\
\text { Text }\end{array}$ \\
\hline
\end{tabular}


REFERENTIAL CHOICE IN THE DISCOURSE OF NATIVE, NEAR-NATIVE AND

NON-NATIVE SPEAKERS OF ENGLISH: REVISITING KIBRIK'S APPROACH

\begin{tabular}{|c|c|c|c|c|c|c|}
\hline $\begin{array}{l}\text { Present } \\
\text { referenti } \\
\text { al forms }\end{array}$ & $\begin{array}{l}\text {-FULL } \\
\text { NP } \\
\text { ONLY } \\
- \\
\text { PRONOU } \\
\text { N ONLY }\end{array}$ & $\begin{array}{l}\text {-FULL } \\
\text { NP } \\
\text { ONLY } \\
- \\
\text { PRONOU } \\
\text { N ONLY } \\
- \\
\text { PRONOU } \\
\text { N? NP }\end{array}$ & $\begin{array}{l}\text {-FULL } \\
\text { NP } \\
\text { ONLY } \\
- \\
\text { PRONOU } \\
\text { N ONLY } \\
- \\
\text { PRONOU } \\
\text { N? NP }\end{array}$ & $\begin{array}{l}\text {-FULL } \\
\text { NP } \\
\text { ONLY } \\
- \\
\text { PRONOU } \\
\text { N ONLY }\end{array}$ & $\begin{array}{l}\text {-FULL } \\
\text { NP } \\
\text { ONLY } \\
- \\
\text { PRONOU } \\
\text { N ONLY } \\
- \\
\text { PRONOU } \\
\text { N? NP }\end{array}$ & $\begin{array}{l}\text {-FULL } \\
\text { NP } \\
\text { ONLY } \\
- \\
\text { PRONOU } \\
\text { N ONLY }\end{array}$ \\
\hline $\begin{array}{l}\text { Missing } \\
\text { referenti } \\
\text { al forms }\end{array}$ & \begin{tabular}{l}
\multicolumn{2}{l}{-FULL } \\
$\mathrm{NP}$ OR \\
PRONOU \\
$\mathrm{N}$
\end{tabular} & \begin{tabular}{l}
\multicolumn{2}{l}{-FULL } \\
NP OR \\
PRONOU \\
$\mathrm{N}$
\end{tabular} & 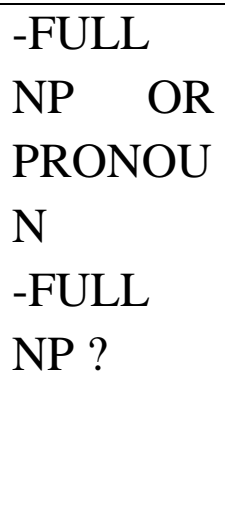 & 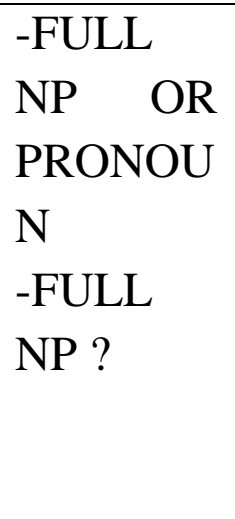 & $\begin{array}{lr} & \text { FULL } \\
\mathrm{NP} & \text { OR } \\
\mathrm{PRONOU} \\
\mathrm{N} \\
\text {-FULL } \\
\mathrm{NP} \\
\mathrm{PRONOU} \\
\mathrm{N}\end{array}$ & $\begin{array}{lr}- & \text { FULL } \\
\mathrm{NP} \quad \text { OR } \\
\text { PRONOU } \\
\mathrm{N} \\
\text {-FULL } \\
\mathrm{NP} \\
\text { PRONOU } \\
\mathrm{N}\end{array}$ \\
\hline $\begin{array}{l}\text { Average } \\
\text { F0 } \\
\text { Range }\end{array}$ & $136.55 \mathrm{~Hz}$ & $359.93 \mathrm{~Hz}$ & $235.18 \mathrm{~Hz}$ & $279.28 \mathrm{~Hz}$ & $182.22 \mathrm{~Hz}$ & $277.93 \mathrm{~Hz}$ \\
\hline $\begin{array}{l}\text { Average } \\
\text { Full } \\
\text { Activatio } \\
\text { n Score } \\
\text { (FAS) }\end{array}$ & 4.09 & 4.11 & 3.07 & 5.55 & 3.14 & 3.55 \\
\hline
\end{tabular}

A number of points can be surmised from the above table. As for native-speakers' discourse, it appears that the category of FULL NP OR PRONOUN is missing. This may be due to the fact that the production of the discourse is governed by a high degree of coherence, where optional processes of WM are not possible. In native discourse, WM is either in control or operating at the maximum level of capacity to accommodate referential shifts. The two operations provide an ideal processing spectrum for WM. There is also the category of PRONOUN ONLY, 
which has almost the same value for both Obama's and Ardren's speeches, viz. 7.98 and 7.92 , respectively.

This is similar to the near-native discourse, where the FULL NP OR PRONOUN category is also missing, yet the value for PRONOUN ONLY one is very high, i.e. 10.88. Moreover, both FULL NP ? PRONOUN and FULL NP OR PRONOUN are absent in the two instances analyzed. This picture negatively impinges on the coherence of the discourse, rendering the referential spectrum fuzzy. The WM operations are likewise affected, since it operates on the capacity level alone, with no control operations detected. In other words, the referential choices are governed by what is retained in memory, not what is retrieved by means of controlling the coherence or logical flow of discourse.

The two categories of FULL NP ? PRONOUN and FULL NP OR PRONOUN are absent in the non-native discourse, while FULL NP ONLY and PRONOUN ONLY assume a high profile. This is similar to native discourse, yet the FAS scores for both categories differ. The FAS scores are lesser for both than for native discourse: this renders the non-native discourse less coherent. Furthermore, the WM operations fluctuate between control and capacity: this may indicate inconsistency in the integrity of referential choices.

Moreover, the FAS is higher for most native speakers than non-native ones, except for the case of Queen Rania's text, where the FAS is 5.55. A similar aberration is detected in the average F0 range, where the highest is $359.93 \mathrm{~Hz}$, being attributed to Jacinda Ardern's Text. These marked deviations may be explained in the light of individual fluctuations in some parts in the discourses examined, since speakers, whether native or not, sometimes deviate from the norms of coreferences and normal intonational contours, and cannot be taken as desiderata of indicative significance.

\section{Conclusions}

It can be concluded that the proposed model has proved amenability to application as regards measuring the integrity of referentiality in three types of discourse examined. The sub-divisions of the potential referential forms to include frequency levels and F0 have also exhibited, to a great extent, how referentiality can be 
utilized to detect the structure of discourse produced by native, near-native and non-native speakers of English.

In the case of native-speaker discourse, the missing category of FULL NP OR PRONOUN can be compensated by the WM operating as control or maximally in full capacity to accommodate the excessive dependence on cataphora. This renders native discourse as based on a shared world knowledge between the speaker and the audience, thus foregrounding the category of PRONOUN ONLY the most prominent in the making of a discourse structure governed by cohesion rather than coherence.

This is not the case for near-native discourse, where both FULL NP ? PRONOUN and FULL NP OR PRONOUN categories are absent. There is thus an over-reliance on FULL NP, which reflects a discourse structure based on cautious moves: the use of referential forms without a clear co-reference (i.e. cataphora) produces a discourse not shared with the audience, but governed, mutatdis muntadis, by the speaker's dubiety about how coherence alone can shape discourse structure. The net result is a WM operating on its capacity level, and not in control of the discourse, since little discourse segments, so to say, remain active.

An even less coherent discourse is produced by non-native speakers. Both categories of FULL NP ONLY and PRONOUN ONLY are not there, which highlights the incomplete operations of the WM. The erratic operations of capacity and control indicate the inability of the WM to retain a fair amount of discourse segments at disposal to strike a balance between form (cohesion) and content (coherence), and can thus lead to forgetting.

It is also of note that the FAS score, as including the acoustic dimension of F0, is amenable to application to other types of discourse. Due to the delimitations of the present study, the three types examined herein have been selected to show how Kibrik's model can be modified to accommodate acoustics. This lends the new model an added value related to its operability to both written and spoken discourse. Other further studies can be done to utilize this new model to investigate specific genres to show how they are structured in terms of referentiality. 


\section{References:}

\section{Primary Sources:}

Jordan King Abdullah II FULL SPEECH: Ideologies of hate distort the word 'God'. https://www.youtube.com/watch?v=m2x3HkEuH3g

Midyear 2018 Undergraduate Commencement Keynote Speech | Naguib Sawiris. https://www.youtube.com/watch?v=xo3ItNRpF18

Prime Minister Jacinda Ardern has just addressed the United Nations General Assembly in New York. https://www.newsroom.co.nz/2018/09/27/256105/fulltext-pms-speech-to-the-united-nations.

Also on YouTube: https://www.youtube.com/watch?v=2_wew4_C3p8.

Queen Rania Speech The Women's Conference 2007. https://www.queenrania.jo/en/media/speeches/california-governor-and-first-ladyswomen\%E2\%80\%99s-conference. Also on YouTube: https://www.youtube.com/watch?v=a3PEgmlQBpE

Remarks by the President at 9/11 Museum Dedication. https://obamawhitehouse.archives.gov/the-press-office/2014/05/15/remarkspresident-911-museum-dedication. Also on YouTube: https://www.youtube.com/watch?v=5ULtHI3zXXk\&feature=emb_title

\section{Secondary Sources:}

Carlson, L., Marcu, D. , and Okurowski, M. 2003. Building a discourse-tagged corpus in the framework of Rhetorical Structure Theory. In Jan van Kuppevelt and Ronnie Smith (eds.), Current Directions in Discourse and Dialogue. Dordrecht: Kluwer.

Chafe, W. 1976. Givenness, contrastiveness, definiteness, subjects, topics, and point of view. Subject and topic, ed. by C. N. Li, 25- 56. New York: Academic Press Inc.

Chafe, W.1994. Discourse, consciousness, and time. Chicago: Chicago University Press. 
Chiarcos, C., \& Krasavina, O. 2005. Rhetorical distance revisited: A pilot study. Proceedings of Corpus Linguistics 2005.

El-Zawawy, A. 2016. Studies in contrastive linguistics and stylistics. Novinka: New York.

Fox, B., 1987a. Discourse Structure and Anaphora. Cambridge: Cambridge University Press.

Fox, A. 1983 . Topic continuity in Biblical Hebrew narrative. Topic continuity in discourse: A quantitative cross-language study, 3, 215-254.

Givón, T. 1983. Topic continuity in discourse . Amsterdam: John Benjamins.

Grosz, B., \& Sidner, C. L. .1986. Attention, intentions, and the structure of discourse. Computational linguistics.

Grüning, A., \& Kibrik, A. A. 2005. Modeling referential choice in discourse: A cognitive calculative approach and a neural network approach. http://epubs.surrey.ac.uk/713378/1/gruening_04.pdf

Hu, J., \& Pan, H. (2001, February). Processing local coherence of discourse in centering theory. In Proceedings of the 15th Pacific Asia Conference on Language, Information and Computation (pp. 139-150).

Huggingface, https://huggingface.co.

Kibrik, A. A. 2000. A cognitive calculative approach towards discourse anaphora. In P. Baker, A. Hardie, T. McEnery and A. Siewierska (eds.), Proceedings of the Discourse anaphora and anaphor resolution conference (DAARC2000). Lancaster: University Centre for Computer Corpus Research on Language.

Kibrik, Andrej A., 1999. Reference and working memory: Cognitive inferences from discourse observation. In K. van Hoek, A.A. Kibrik, and L. Noordman (eds.), Discourse Studies in Cognitive Linguistics. Amsterdam and Philadelphia: John Benjamins. 
Kibrik, A. A. 2000. Cognitive discourse analysis: Some results. Paper presented at the $7^{\text {th }}$ International Pragmatics Conference. Budapest, July 2000.

Kibrik, A.A., \& Krasavina,O.N.(2005).A corpus study of referential choice: the role of rhetorical structure. Papers from the Annual International Conference "Dialogue": Computational Linguistics and Intellectual Technologies, eds I.M.Kobozeva, A.S.Narin'jani, and V.P.Selegey (Moscow:Nauka), 561-569.

Kibrik, A.A., Podlesskaja, V.I. (Eds.) .2009. Night Dream Stories: A corpus study of spoken Russian discourse. Moscow: Jazyki slavjanskix kul'tur.

Kibrik, A.A., Dobrov,G.B., Zalmanov, D.A., Linnik,A.S., \& Loukachevitch, N. V.2010."Referencial' nyjvyborkakmnogofaktornyjverojatnostnyjprocess [Referential choiceasamulti-factorial probabilistic process],"in Proceedings of the Papers from the Annual International Conference "Dialogue" (2010), Bekasovo: Computational Linguistics and Intellectual Technologies, ed.A.E. Kibrik (Moscow:Izdatel'stvoRGGU),173-181.

Kibrik, A. A. 2011. Cognitive discourse analysis: local discourse structure. In Slavic linguistics in a cognitive framework (pp. 273-304).

Kibrik, A., \& Fedorova, O. 2018, May. A «Portrait» Approach to Multichannel Discourse. In Proceedings of the Eleventh International Conference on Language Resources and Evaluation (LREC 2018).

Krasavina, O.N. 2006 "Multi-factorial choices inspeaking," in The Second Biennial Conference on Cognitive Science, eds B.M.Velichkovsky,T.V. Chernigovskaya,Yu.I. Aleksandrov, and D.N.Akhapkin (Saint-Petersburg: Saint Petersburg State University, Philological Faculty), 86-87.

Krasavina, O.N., \& Chiarcos,C. .2007. "PoCoS: potsdam coreference scheme," in Proceedings of the Linguistic Annotation Workshop, Prague, (Stroudsburg, PA: Association for Computational Linguistics),156-163.

Mann, W., Christian M., and Sandra A. T. 1992. Rhetorical structure theory and text analysis. In W. Mann and S. Thompson (eds.), Discourse Description. Diverse Linguistic Analyses of a Fund-raising Text. Amsterdam and Philadelphia: John Benjamins. 
Linguapress. http://linguapress.com .

Loukachevitch, N.V., Dobrov, G.B., Kibrik, A.A., Khudyakova, M.V., \& Linnik, A.S.2011. "Factors of referential choice: computational modeling," in Proceedings of the Papers from the Annual International Conference "Dialogue" (2011): Computational Linguistics and Intellectual Technologies, ed. A.E. Kibrik. (Moscow:Izdatel'stvoRGGU),458-467.

Marcu, D. (2000) Extending a formal and computational model of Rhetorical Structure Theory, in Proc. 18th Int. Conf. on Computational Linguistics (COLING'2000).

Moser, M. and J. Moore (1996) Toward a synthesis of two accounts of discourse structure. Computational Linguistics 22(3):409-419.

Readability Formulas. https://readabilityformulas.com

Tetreault, J. and J. Allen .2003. An empirical evaluation of pronoun resolution and clausal structure, in Proc. 2003 Int. Symp. on Reference Resolution and its Applications to Question Answering and Summarization, 1-8.

Tomlin, R., 1987. Linguistic reflections of cognitive events. In R. Tomlin (ed.), Coherence and Grounding in Discourse. Amsterdam and Philadelphia: John Benjamins.

Wolf, T., Debut, L., Sanh, V., Chaumond, J., Delangue, C., Moi, A., Cistac, P., Rault, T., Louf, R., Funtowicz, M. and Brew, J., 2019. Transformers: State-ofthe-art natural language processing. arXiv preprint arXiv:1910.03771. 


\section{الاختيار الإحالي في خطاب المتحدثين الأصليين للغة الإنجليزية وشبه المتحدثين بها وغير الناطقين بها: إعادة النظر في مقاربة كيبريك الإين د. عمرو منصور الزواوي \\ أستاذ مساعد، قسم اللغة الإنجليزية كلية التربية، جامعة الاسكندرية}

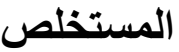

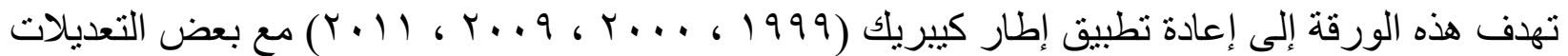

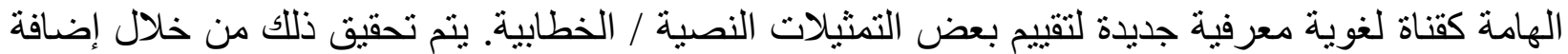

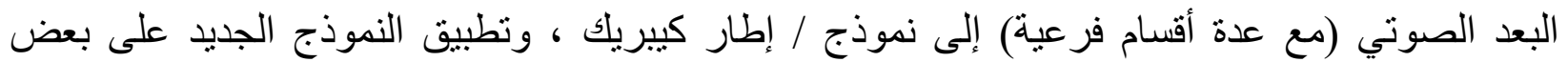
الخطب. تم اختيار هذه الخطب بحيث تمثل مخرجات من قبل المتحدثين الأصليين للغة الإنجليزية وشبه

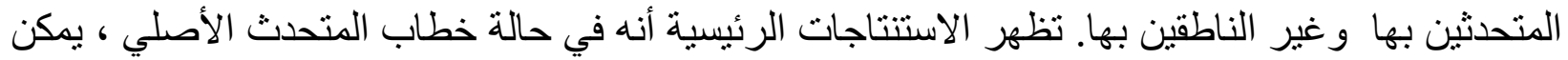

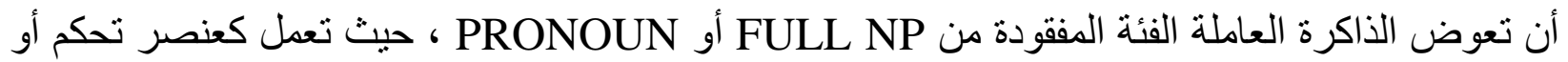
بأقصى طاقتها لاستيعاب الاعتماد المفرط على الإحالة المسبقة. ولكن ليس هذا هو الحال بالئ بالنسبة للخطاب

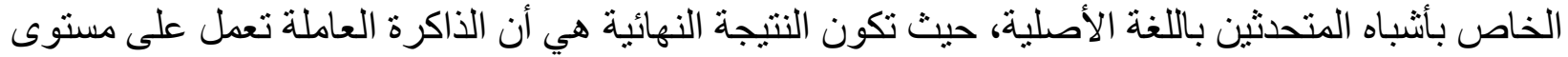

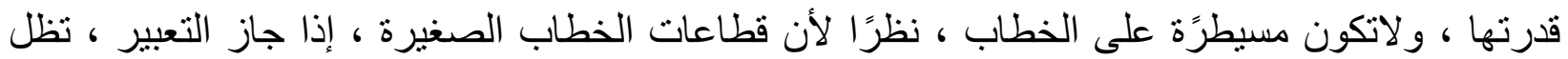

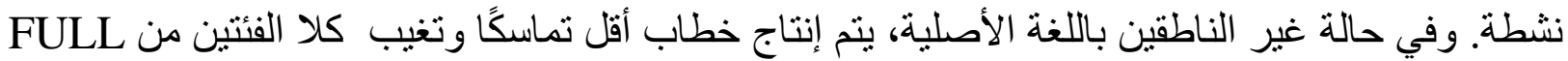
PRONOUN ONLY وNP ONLY ، مما يسلط الضوء على العمليات غير المكتملة الذاكرة العاملة. الكلمات المفتاحية: إطار كيبريك العصبي ؛ الذاكرة العاملة؛ التلاحم؛ التنشيط؛ صوتيات 